\title{
Dounreay Shuftier Diagnostic Software Operations Manual
}

\author{
G.W. Eccleston \\ B. Stuewe \\ S. Klosterbuer \\ T. Van Lyssel
}

\section{DISCLAIMER}

\begin{abstract}
This report was prepared as an account of work sponsored by an agency of the United States Government. Neither the United States Government nor any agency thereof, nor any of their employees, makes any warranty, express or implied, or assumes any legal liability or responsibility for the accuracy, completeness, or usefulness of any information, apparatus, product, or process disclosed, or represents that its use would not infringe privately owned rights. Reference herein to any specific commercial product, process, or service by trade name, trademark, manufacturer, or otherwise does not necessarily constitute or imply its endorsement, recommendation, or favoring by the United States Government or any agency thereof. The views and opinions of authors expressed herein do not necessarily state or reflect those of the United States Government or any agency thereof.
\end{abstract}

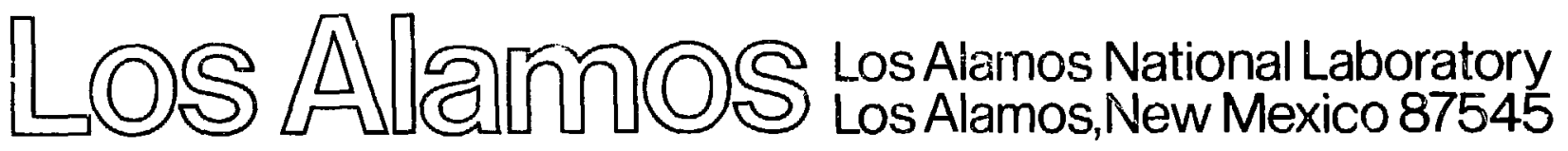


ABSTRACT . . . . . . . . . . . . . . . . . . . . 1

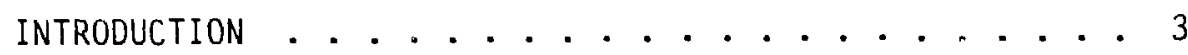

SHUFFLER DESCRIPTION . . . . . . . . . . . . . . . . 4

System Configuration ... . . . . . . . . . 4

Programs ..................... 4

PET Computer . . . . . . . . . . . . . . . 6

Harwe11 MOUSE ................. . . 6

SMC Module................... . . 6

Connector Slots............... . . 6

Reset Button ................ 7

Sensor Lights . . . . . . . . . . . . . . 7

Mechanical System ................ 8

${ }^{252} \mathrm{Cf}$ Source ................ 8

Instrument Power ................ 9

TEST PROGRAM NDA5TST . . . . . . . . . . . . 10

Program Function . . . . . . . . . . . . . . i0

Start the System . . . . . . . . . . . . . 10

Load A Program . . . . . . . . . . . . . 10

Run The Program ................ 10

To Get Out ............... . 10

Commands and Menus.................. 11

Selecting Commands . . . . . . . . . . . 11

TEST PROGRAM NDA5TST COMMAND MENU . . . . . . . . . 12

Program Start-up................ . . 12

Command Menu .................. 12

TEST PROGRAM NDA5TST COMMAND EXPLANATIONS . . . . . . 13

Command Explanations .............. . . 13

A - Assay Cycie Simulation......... 13

T - Test Cable Sensors......... . . 13 


\section{CONTENTS (Cont)}

L - List System Status . . . . . . . 13

R - Restart Stepping Motor Control Module . . . . 14

0 - Turn Stepping Motor On . . . . . . . 14

F - Turn Stepping Motor off . . . . . . . 14

P - Position Source at Storage Location . . . . 14

I - Move Source to Irradiation Position .... . . 14

S - Move Source to Storage Position ...... 15

M - Move Source N Inches . . . . . . . 15

B - Block All Cable Sensors . . . . . . . 15

U - Unblock All Cable Sensors . . . . . . . 16

D - Irradiation Position Repeatability Test . . . 16

C - Send a Conmend to the Shuffler. . . . . . 16

Z - Change Timer Frequency. . . . . . . . 19

$X$ - Exit from NDA5TST . . . . . . . . 19

NDA5TST CODE DESCRIPTION . . . . . . . . 20

Summary .............. . . 20

Structure ................. 20

Documentation ................ 20

Code Description . . . . . . . . . . 20

Program Header .............. . . 21

Start-up Subroutine ............ 21

Menu Subroutine.............. 21

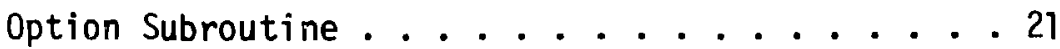

Assay Subroutine .............. . . 21

Sensor Test Subroutine . . . . . . . . 22

Single-Step Subroutine . . . . . . . 22

Status Subroutine............. 23

Clock Frequency Subroutine ......... 23

Motor On Subroutine........... 23

Motor Off Subroutine ...........23

Irradiation Transfer Subroutine . . . . . . 23

Storage Transfer Subroutine ......... 23 
CONTENTS (cont,)

Position Source at Storage Subroutine . . . . . 24

Single-Command Subroutine . . . . . . . . . 24

Position Repeatability Subroutine....... 24

Communications Subroutine . . . . . . . . . . 24

Read MOUSE Inputs Subroutine ........ 25

Read MOUSE Outputs Subroutine ........ 25

Set MOUSE Outputs Subroutine ........ 25

Shuffler Restart Subroutine . . . . . . . . 26

MOUSE Control Subroutine ..........26

APPENDIK A CALIFORNIUM SOLRCE . . . . . . . . 27

Description . . . . . . . . . . . 27

Californium-252 . . . . . . . . . . 27

Shuffler Source ............. . 27

Cable Attachment . . . . . . . . . . . . 27

Shipment . . . . . . . . . . . . . 27

Shipping Cask ............. . . 27

Source Transfers . . . . . . . . . . . 28

Practice with Dummy Source . . . . . . . . 28

Procedure .............. 28

APPENDIX B DESIGN ELECTRONICS . . . . . . . . . 32

Control Electronics . . . . . . . . . . . 32

Irradiation Source Position Adjustmant . . . . . . 32

Switch Settings ............. . 32

Add 12 Steps ................. 33

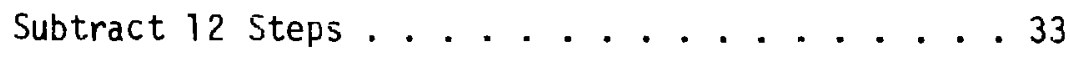

Signal Lines . . . . . . . . . . . . . . . 33

MOLISE Input/Output Lines . . . . . . . . 33

Output Lines . . . . . . . . . . . . . . 33

Input Lines.............. . . 34

Distribution-Box Wiring . . . . . . . . . 34

Power Supply Wiring ............ . 36 


\section{CONTENTS (cont)}

Changing Wiring to $240 \mathrm{Vac}$. . . . . . . . . 36

Changing Wiring to $120 \mathrm{Vac}$. . . . . . . . 36

Schematics and Commercial Components . . . . . . . 37

Electrical Schematic............ . . 37

Mechanical Schematics ............ . 37

Commercial Equipment ............... 4 41

APPENDIX C ERROR MESSAGES .............. . . 42

Error Message Explanation . . . . . . . . . . . 42

Error No. 11: Invalid Command

Sent by PET Computer . . . . . . . . . . . 42

Error No. 12: Check Sensors,

Power Supfly, and Motor Status . . . . . . . 4 42

Error No. 13: Over-Travel Sensor

Failed to Stop Steps . . . . . . . . . . . 42

Error No. 14: Encoder Failed to Provide

Step-Completion Signal . . . . . . . . . . . 42

Error No. 15: Encoder Provided Excess

Step-Completion Signal . . . . . . . . . . . . 43

APPENDIX D SOFTWARE COMMUNICATIONS . . . . . . . 44

Pet-to-Shuffler Communications . . . . . . . . . 44

PET-to-Shuffler Message Format . . . . . . . . 44

PET Messages . . . . . . . . . . . . . . . . . 44

SMC Messages . . . . . . . . . . . . . . . . 44

Message Synchronization .............. 44

Command Processing . . . . . . . . . . . . 4 46

Communications Example... . . . . . . . . . 4 46

Communication Subroutines.......... 46

Sample Code Description .......... . 49

Communication Errors.............. 52

MOUSE Communications ................ 52

Introduction ................ 52 


\section{CONTENTS (cont)}

Convert from ASCII to Decimal . . . . . . . . 52

SMC Messages ................... 53

Read MOUSE Inputs Subroutine ............. 53

Read MOUSE Outputs Subroutine . . . . . . . . . 53

Send Command C Subroutine . . . . . . . . . 54

SMC Reset ................. . 54

Additional Information .............. 54

APPENDIX E NDA5TST CODE LISTING . . . . . . . . . 55 
DOUNREAY SHUFFLER DIAGNOSTIC

SOF TWARE OPERATIONS MANUAL

by

G. W. Eccleston, B. Stuewe,

S. Klosterbuer, and T. Van Lyssel

\begin{abstract}
This operations manual describes the test software for the Dounreay Shuffler. The Shuffler is an assay system, controlled by a Commodore PET computer, that measures the plutonium content in leached hulls at the fuel reprocessing plant in Dounreay, Scotland. The Shufiler contains a $252 \mathrm{Cf}$ neitron source that is moved between storage and irradiation locations to obtain measurement data. A stepping motor contro] (SMC) module operates the Shuffler and accepts commands from the PET to move the source. This manual briefiy describes the Shuffler and provides details on running and using the diagnostic software test program. The communications protoco? for message transmittal between the PET and SMC is defined and a detailed example of message sending is presented in an appendix.
\end{abstract}







The Dounreay Shuffler is designed to nondesiructively measure the plutonium content in leached hulls at. the Dounreay, Scotland, Prototype Fast Reactor (PFR) fuel reprocessing facility. The hulls are measured in a 200-mm-diam by $1-m-t a l l$ stainless steel basket. The hot cell crane automatically handles and positions the basket for measurements. The baskets are measured by scanning them in 100-mm segments.

The figure on the facing page is a photograph of the Dounreay Shuffler assay system. A stepping motor control (SMC) module mounted in a Harwell 6000 series crate controls the Shuffler.

The assay of plutonium content consists of collecting a neutron background and then running a cyclical sequence to measure delayed neutrons. This sequence starts with the ${ }^{252} \mathrm{Cf}$ neutron source moving to an irradiation position near the sample. In this source position, fissions will be induced in the plutonium in the sample. Following the irradiation period, the source is moved to the storage position, and delayed neutrons resulting from plutonium fissions are counted. This irradiation-and-counting sequence is continued for the number of cycles specified by the operator. The sample is then moved to the next segment, and the measurement procedure is repeated. After the measurements are completed, the delayed-neutron counts are summed and, with a calibration fit, the plutonium mass in the sample is determined.

This manual describes the software that tests each component of the Dounreay Shuffler assay system. The manual is primarily a reference document for the Shuffler diagnostic program. A complete listing of the NDA5TST diagnostic program is in Appendix E. Detailed information on the complete system and the assay program is in the Harwell System NDA5 operations manual for the neutron interrogation system. 

are shown in Fig. 1. Table I lists the components and gives a brief description.

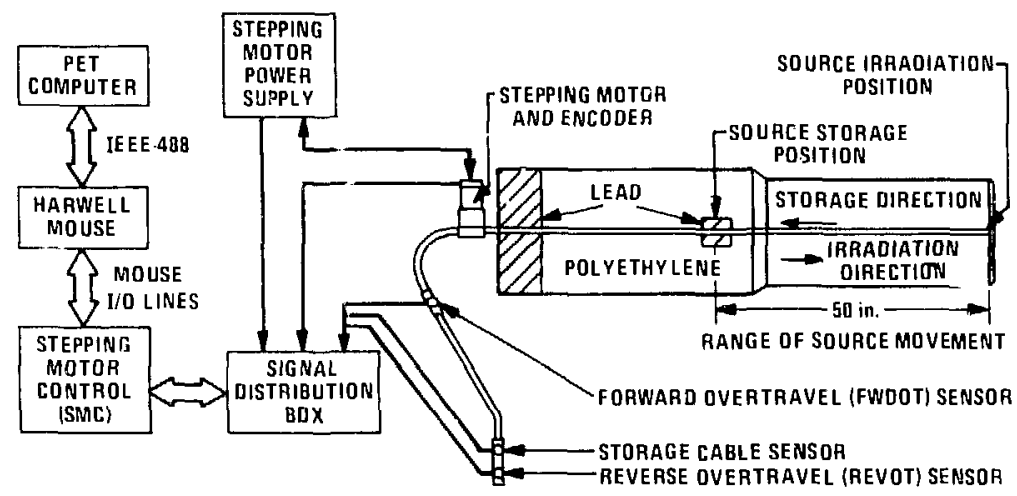

Fig. 1. Shuffler component diagram.

\section{PROGRAMS}

The following programs supplied with the Shuffler are contained on a floppy diskette:

$$
\begin{array}{ll}
\text { Diagnostic program document } & \text { - NDA5TST.DOC } \\
\text { Diagnostic program } & \text { - NDA5TST } \\
\text { Example assay program document } & \text { - NDA5LA.DOC } \\
\text { Example assay program } & \text { - NDA5LA. }
\end{array}
$$

The document files (NDA5TST.DOC) and (NDA5LA.DOC) briefly describe the NDA5TST and NDA5LA programs. The diagnostic program (NDA5TST) operates and tests the Shuffler to help isolate problems. NDA5LA is a program containing examples that illustrate features required in the Shuffler assay program. 
TABLE I

SHUFFLER COMPONENT DESCRIPTION

I tem

1. PET computer

2. Harwe11 MOUSE

3. Stepping motor control module (SMC)

4. Signal distribution box

5. Stepping motor

6. Power supply

7. Storage sensor

8. Reverse overtravel sensor

9. Forward overtravel sensor

10. Californium source

11. Teleflex cable

12. Storage position

13. Irradiation position
Description

Runs test and assau orograms

Contains timer, scalers and provides communication between PET and SMC

Motorola 6809 computer card that communicates with the PET and controls the stepping motor

Provides signal interface between stepping motor and SMC

Moves source between store and irradiate positions as controlled by the SMC module

Powers the stepping motor

Senses when the source has reached the storage position (see Fig. 1)

Senses when the source has reached the reverse overtravel position (see Fig. 1)

Senses when the source has reached the forward overtravel position (see Fig. 1)

Neutron source to provide sample irradiation

Connected to source and runs through gear attached to stepping motor to allow source movement

Shielded position in center of tube Position at end of tube near sample 
PET COAPUTER

HARHELL MOUSE

SHC MODULE

Connector Slots
The PET computer runs the test and assay programs. The PET sends commands to the SMC module through the Harwell MOUSE module to transfer the source to either the irradiation or the storage position for measurements.

The MCUSE module was developed by Harwell and contains a timer, scalers, and input/output ( $1 / 0)$ lines. The high byte of the I/O lines is used to communicate between the PET and SMC. The low byte is not used in these comminications.

The SMC module contains a Motorola 6809 micronrocessor and digital logic to control the Shuffler. The module interfaces with the Shuffler through a signal distribution box. Software contained in read-only memory (ROM) in the SMC module communicates with the PET coriputer through the MOUSE I/O lines. The software controls movement of the ${ }^{252} \mathrm{Cf}$ source contained in the Shuffler.

A front-panel view of the SMC module is shown in Fig. 2 (see also Fig. B-1 in Appendix B). The front Danei contains two connector slots ( $P 1$ and $P 2)$. Connector $P 1$ accepts a ribbon cable that routes the Shuffler control lines to the signal distrihution box. Connector P2 accepts a nonstandard RS232 connector and allows a terminal to directly control and test the module. 


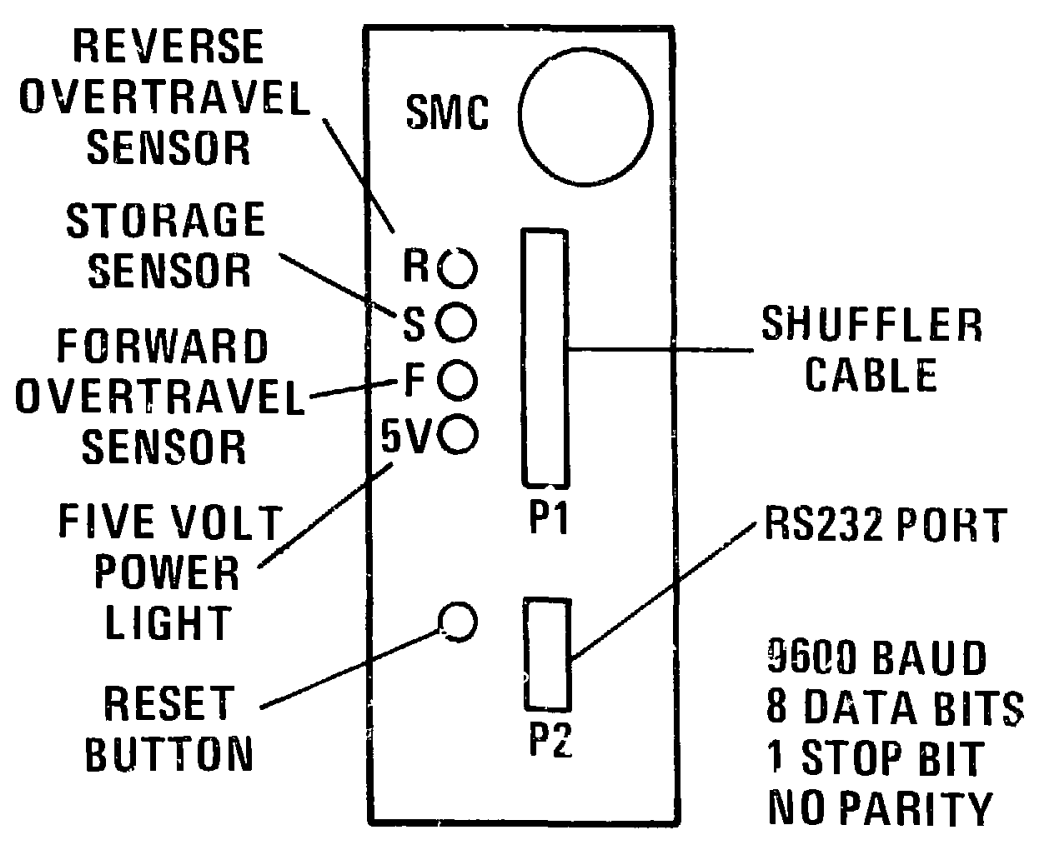

Fig. 2. Front panel of the SMC module.

Reset Button

Sensor Lights
The RESTT push-button switch on the front panel allows the Motorola computer software in the SMC module to be manually reset and initialized. Push this button when the system is initially started or not performing properly.

The red $F$ and $R$ iight-emitting-diodes (LEDs) on the front panel indicate that the source cable has moved too far in either the forward (F) or reverse $(R)$ direction. When the forward ovar-travel sensor is unblocked, the F LED turns on. When the reverse over-travel sensor is blocked, the R LED turns on. The motor is stopped when one of these sensors is triggered. The green (S) LED comes on when the storage position sensor is blocked by the end of the source cable and indicates that the 
Sensor Lights

(cont) source is in the storage position. The LED labeled $5 \mathrm{~V}$ shows that the module has $5-V$ power.

NOTE: When the source is in the storage position, the proximity sensors should read:

Reverse over-travel sensor -- Unblocked $\rightarrow$ LED of $f$ Storage sensor --..--.--- Blocked $\rightarrow$ LED on Forward over-travel sensor -- Blocked $\rightarrow$ LED of $f$

The mechanical portion of the Shuffler is constructed primarily from polyethylene and lead, and it fits into the hot cell port in the existing PFR fuel reprocessing facility in Dounreay. The Shuffler contains a tube that guides a ${ }^{252} \mathrm{Cf}$ neutron source between the $s^{t}$.orage and irradiation positions. The source is connected to a Teleflex cable and is moved by a gear attached to a stepping motor. Three proximity sensors mounted on the cable takeup tube detect the end of the cable and provide control infurmation for positioning the source in the instrument (see description of sensor lights above).

${ }^{252}$ Cf SOURCE

The Shuffler contains a ${ }^{252} \mathrm{Cf}$ neutron source. Initially, this source contained approximately $3 \mathrm{mg}$ of ${ }^{252} \mathrm{Cf}$ emitting $7.0 \times 10^{9} \mathrm{n} / \mathrm{s}$. Therefore, the source emits a large quantity of radiation and requires shielding for personnel protection. To ensure that the scurce is always completely shielded and kept inside the instrument, its 
${ }^{252}$ Cf SOURCE

(cont) movement is limited by using over-travel position sensors and mechanicai stops. These stops prevent the source from moving past the reverse overtravel sensor. Appendix A contains a detailed description of the source and instructions for replacing the source in the Shuffler.

The SMC module sits in and draws $5 \mathrm{~V}$ of nower from a Harwell Series 6000 crate. The stepping motor power supply is wired for $120-\mathrm{Vac}, 50-\mathrm{Hz}$ power. The power supply can be wired to operate from 240 Vac. Appendix B contains the descriptions and specifications of the design electronics, including the wiring schematic for the power supply. 
PROGRAM FUNCTION

START THE SYSTEM

LOAD A PROGRAM

RUN THE PROGRAM

TO GET OUT

(EXIT A PROGRAM)
NDA5TST is a diagnostic program that allows each feature of the Dounreay Shuffiler to be individually operated and tested.

Start the Shuffler instrument by turning on the ac power to the following modules:

- PET computer,

- Harwell 6000 series crate, and

- SMC module power supply.

P1ace a floppy disk containing program NDA5TST into disk drive unit 0 . To load program NDA5TST, type

\section{DLOAD"NLA5TST",DO (RETURN)}

WOTE: The (RETURN) symbol means that you must press the return key on the PET keyboard.

To run the basic pirogram, type

RUN (RETURN)

Anytime you need to stop and exit a program, type $X($ RETURN $)$ 
COMUANDS AND MENUS

SELECTING COFMANDS
Progräm NDA5TST prints a SELECT COMMAND message requesting a command:

SELECT COMMAND (H FOR HELP) $\rightarrow$ ?

The $H$ for HELF option lists a menu of available commands (see p. 9). Type H(RETURN) to get this 1ist. Each time the program completes a colmand, it prints the SELECT C.OMMAND message and waits for you to type a new command.

To give the compucer a command, type the correct letter (shown on the menu) and then press (RETURN). For example, to enter the command "BLOCK ALL SENSORS" in the NDA5TST program, type

B (RETURN) 
PROGRAM START-UP

COMMAND MENU
Running the NDA5TST program initiates a start-up sequence that resets the MOUSE module, resets the SMC module, checks that the stepping motor power supply is on, reads and displays the Shuffler status, waits $5 \mathrm{~s}$, and then prints the command menu. Your interaction is required only if the stepping motor power supply is off.

Type H(RETURN) at the SELECT COMMAND prompt to list the following command menu on the PET screen:

DIAGNOSTIC MENU

SELECT COMMAND (H FOR HELP) $\rightarrow$ ? 


\section{COMWAMD EXPLANATIONS}

A - Assay Cycle Simulation

$T$ - Test Cabl 2 Sensors
The A option tests the Shuffler assay cycle and MOUSE scalers. This assay test lists background count rates, source transfer times, and the times and count rates associated with irradiation and delayed-neutron cycles.

The T option uses the stepping motor, stepping slowiy, to unblock and then block the three proximity sensors. The test determines if the sensors are able to correctly detect when they are blocked and unblocked by the cable. Sensor errors are printed on the PET screen. Refer to p.4 for a description of the sensors.

L - List System Status The L option lists the Shuffler instrument status. This list contains the following information:

- Location of the ${ }^{252} \mathrm{Cf}$ source,

- Stepping motor power (on or off),

- Proximity sensor status (blocked or unblocked),

- Last command sent to the SMC,

- Current command at the SMC,

- Last reply received from the SMC,

- Shufflei error status, and

- MOUSE error status. 
R - Restart Stepping Motor Control Module

i) Turn Stepping motor On

F - Turn Stepping $\therefore$ s. Off

P - Position Source at Storage Location

I - Move Source to Irradiation Position
The $R$ option resets the MOUSE module and sends a nonmaskable interrupt to the Motorola computer in the SMC module. This interrupt resets the Motorola software, moves the source to storage, and waits for a command from the PET computer. Errors received during the reset are listed on the PET screen.

The 0 option turns the stepping motor power on.

The $F$ option turns the stepping motor power off. The motor power should be turned off when the stepping motor is not being used to reduce heating of the motor and noise.

The $\mathrm{P}$ option turns the stepping motor power on, moves the source to storage, positions it at the storage sensor, and then turns the motor power off.

The I option turns the stepping motor power on, positions the source at the storage sensor, moves the source rapidly from the storage to the irradiation position, and then turns the motor power off.

Irradiation source position adjustment--the SMC contains a fixed number of steps (1244) in the ROM software to move the ${ }^{252} \mathrm{Cf}$ source from the storage to the irradiation position. You can adjust the number of steps up to 127 in both direc-. tions with an eight-position rocker switch mounted 
I - Move Source to Irradiation Position (cont)

S - Moye Source to Storage Position on the SMC module. Please refer to the heading Position Adjustment in Appendix $B$ for an example of the stment procedure.

The $S$ option turns the stepping motor power on, moves the source rapidly from the irradiution to the storage position, positions the source at the storage sensor, and then turns the motor power off. If the storage sensor is blocked when you select this option, the source is repositioned at the storage sensor.

The $M$ oftion steps the source a selected distance of $\mathrm{N}$ inches. You selec: $\mathrm{b}$ both the direction and distance to move the source. Movement in the irradiation direction is into the Shuffier, and movement in the storage direction is out of the Shuffier.

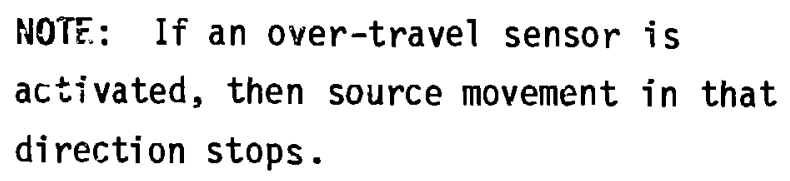

The B option turns the stepping motor power on, moves the source slowiy out of the Shuffler (storage direction) until all the proximity sensors are blocked, and then turns the motor off. sclecting the $L$ option after the B option lists the Shuffler status, showing the status of the sensors. 
U - Unblock A11

D - Irradiation

Position

Repeatability Test
Cable Sensors

The $U$ option turns the stepping motor power on, moves the source slowly into the Shuffler (irradiation direction) until all the proximity sensors are unblocked, and then turns the motor power off. Selecting the L option after the $U$ option lists the Shuffler status, showing the status of the sensors.

The $D$ option tests the repeatability of positioning the source at the irradiation location. You specify the number of times $(N)$ to reposition the source. This option moves the source rapidly from the storage to the irradiation position and then single-steps the motor, counting the number of steps, in the irradiation direction until the forward over-travel sensor is unblocked. This number is printed on the screen and should be repeatable within a few steps. The mean ard the standard deviations of the number of steps to unblock the sensor are calculated and displayed on the PET screen.

NOTE: Accurate repositioning of the irradiation source keeps a more constant neutron flux on the sample and provides better precision in assay measurements.

C - Send a Command to the Shuffler
The $C$ option allows you to select and transmit communication commands from the PET computer to the SMC module and then check for correct transmission with the L option. Selecting the $C$ option prints the following list or. the PET screen: 


\section{C - Send a Command to the Shuffler (cont)}

SHUFFLER COMMANDS

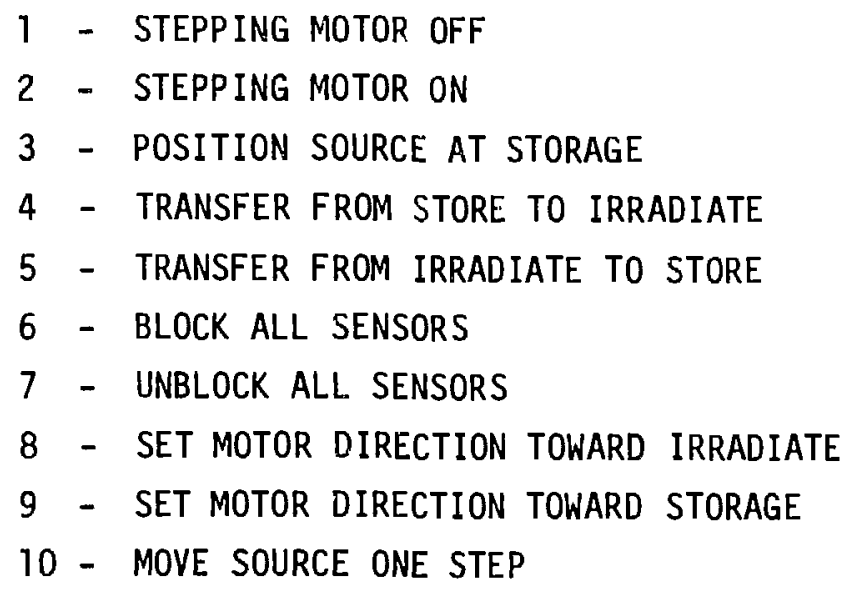

SELECT COMMAND (X TO EXIT H FOR HELP) $\rightarrow$ ?

Command Example A--Using the C option, you can determine whether the stepping motor is taking steps. For example, select movement in the irradiation direction and then make the motor take two steps. The commands you need to select are as tollows: 
C - Send a Command to the Shuffler (cont)
The dialog on the PET screen for the above five commands is as follows:

SELECT COMMAND (H FOR HELP) $\rightarrow$ ?C

SELECT COMMAND (X TO EXIT H FOR HELP) $\rightarrow$ ? 2

SELECT COMMAND(X TO EXIT H FOR HELP) $\rightarrow$ ? 8

SELECT COMMAND (X TO EXIT H FOR HELP) $\rightarrow$ ? 10

SELECT COMMAMN(X TO EXIT H FOR HELP) $\rightarrow$ : 10

CELECT CCMMAND ( $X$ TO EXIT H FOR HELP) $\rightarrow$ ? 1

SELECT COMMAND (X TO EXIT H FOR HELP) $\rightarrow$ ? $X$

SELER,T COMMAND ( $h^{\prime}$ FOR HELP) $\rightarrow$ ?

Command Example B--The command mode tests error conditions. For example, send an invalid command to the Shuffler. The valid commands rarige from zero through ten, so in the command mode input the number 12. The following sequence should appear on tr.a PET screen:

SELECT COMMAND (X TO EXIT H FOR HELP) $\rightarrow$ ? 12. RETURN)

\#11 INYALID COMMAND SENT BY PET COMPUTER

SELECT COMMAND (X TO EXIT H FOR HELP) $\rightarrow$ ?

The second line of the above sequence is an error message. Error message No. 11 indicates that an invalid command was sent. The $C$ option test for error conditions is used to produce error messages either 11, 12, or 14 (see Appendix $C$ for error 
C - Send a Command to the Shuffler (cont)

messages). Another error sitliation vould be attempting to move the source using command 4 without first turning on the motor power supply using command 2. This situation will produce error number 12, a general error.

Command Example C--Usually, you use the I option on the main menu to transfer the source rapidly to the irradiation position. To do the same task using the $C$ command, you must do the following:

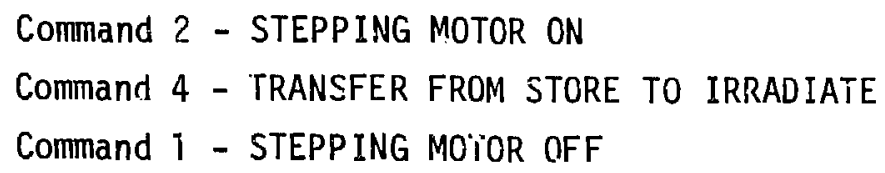

The dialog on the PET screen for the above th "ee commands is as follows:

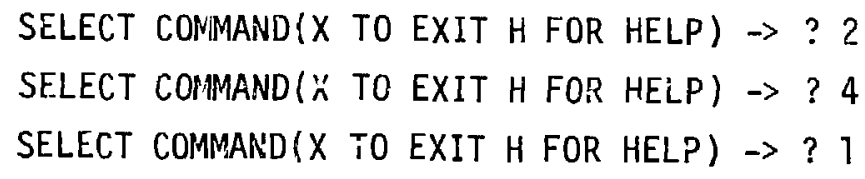

Z - Change Timer Frequency

(Default is $50 \mathrm{~Hz}$ )
The $Z$ option allows you to specify the PET computer clock frequency. This option does not set the frequency directly. The PET internal clock times Shuffler events, and the program must have the correct frequency value to calculate count rates and source transfer times accurately. The clock frequency is gove:ned by the power supply, which will be either 50 or $60 \mathrm{~Hz}$. The default setting in the program is $50 \mathrm{~Hz}$.

$X$ - Exit From NDA5TST Typing $X$ will allow exit from the program. 
SUMTPARY

Structure

Documentation

CODE DESCRIPTION
The NDA5TST code permits the Shuffler to be tested easily and thoroughly. The menu-driven program performs control and test functions using options the operator selects from the menu. The options are input at the PET keyboird.

The software was developed in modules, using structured coding concepts where possible. Each module is an isolated control function and is accessed with subroutine (GOSUB) calls. The subroutines provide examples of how to implement contro? functions in a program.

The NDA5TST program is highly documented with remark (REM) statements on most lines of the code. This manual provides a general description of the subroutines in NDA5TST. A detailed discussion of the code for PET-to-SMC communications is in Appendix D.

A complete listing of the NDA5TST code is in Appendix E. The remark statements should provide sufficient information to understand the operation of the program. A list and description of variables in the program is given in Table D-4 of Appendix $D$. The following discussion describes features of each subroutine in the program. 
Program Header

Lines 100-175

Start-up Subroutine

Lines 180-400

Menu Subroutine

Lines 500-594

Option Subroutine

Lines 600-700

Assay Subroutine

Lines 1000-1220
The program header contains the program name, software creation and revision dates, program purpose, and the variables used in the code. The meanings of the variables are also given and, if restricted, their allowable ranges of values.

The start-up subroutine resets the SMC module, reads the MOUSE inputs to determine the Shuffler status, resets the MOUSE module, and checks that/ the stepping motor power supply is on.

The menu subroutine prints the option menu on the PET screen and a message requesting your input. The program waits until an input is received.

The option subroutine accepts an option command from the PET keyboard and, if allowable, perfoims a call to the selected subroutine.

The assay subroutine requests the following initial information:

$$
\begin{aligned}
& \text { NUMBER OF ASSAY CYCLES TO RUN } \rightarrow ? \\
& \text { DO YOU WANT SCALER OPERATION }(Y \text { OR N) } \rightarrow ?
\end{aligned}
$$

When you select scaler operation with the $Y$ option, the program requests a background count time.

INPUT BACKGROUND COUNT TIME $(0.1$ TO 250 SEC $) \rightarrow$ ?

The irradiation and delayed count times are always input. These values represent the amount of time 
Assay Subroutine (cont)

Sensor Test

Subroutine

Lines 2000-2700

Single-Step

Subroutine

Lines 2790-2990 the source is held at the storage and irradiation positions.

$$
\begin{aligned}
& \text { INPUT IRRADIATION TIME }(0.1 \text { TO } 250 \mathrm{SEC}) \rightarrow ? \\
& \text { INPUT DEIAYED COUNT TIME }(0.1 \text { TO } 250 \mathrm{SEC}) \rightarrow ?
\end{aligned}
$$

When you select scaler operation, the assay option collects a background count for a specified time (defined as TB in the code). This subroutine then completes a total of Al cycles. Each cycle consists of moving the source from storage to irradiation and back to storage. Source transfer times (defined as $\mathrm{Tl}$ and $\mathrm{T} 3$ in the code), irradiation times (T2), delayed-neutron count times (T4), and count rates are collected at each cycle, and the information is printed on the PET screen.

The sensor test subroutine serves only as a diagnostic tool. The test blocks and unblocks the source cable position sensors to determine if the sensors are operating properly.

The single-step subroutine single-steps the source a distance of $\mathrm{N}$ inches in the direction $\mathrm{D}$ selected. In the code, $D=8$ for the irradiation direction and $D=9$ for the storage direction. This subroutine tests for position repeatability, checks that the motor can take single steps, and checks that the motor can move the source, after an assay, further into the Shuffler to dacrease the radiation level. 
Status Subroutine

Lines 3000-3300

Clock Frequency

Subroutine

Lines 3400-3495

Motor On Subroutine

Lines 3500-3510

Motor Off Subroutine

Lines 3550-3560

Irradiation Transfer

Subroutine

Lines $4000-4080$
The status subroutine first reads the MOUSE inputs and outputs, then prints the status of the Shuf fler system on the PET screen.

The clock frequency subroutine allows you to specify the power line frequency (variable FR in the code) for correct timing using the PET jiffy clock. This program does not prij'sically set the clock frequency; it obtains the FR value from your input.

The motor on subroutine sets the variable to a value of 2 (for the variable $C$ in the code) for the Shuffler communications subroutine, which turns the stepping motor power supply on.

The motor off subroutine sends a $C$ value of 1 to the Shuffler communications subroutine, which turns the stepping motor power supply off.

The irradiation transfer subroutine turns the stepping motor power on $(\mathrm{C}=2)$, requests a rapid transfer of the source from storage to irradiate $(C=4)$, and then turns the motor off $(C=1)$. The transfer time (TR in the code) measured with the jiffy clock is converted to seconds by dividing by $F R$ and is printed on the PET screen.

The storage transfer subroutine turns the stepping motor power on $(C=2)$, requests a rapid transfer of the source from irradiate to storage $(C=5)$, and then turns the motor off $(C=1)$. The value of TR measured with the jiffy clock is 
Storage Transfer

Subroutine

(cont)

Position Source at Storage Subroutine

Lines 6000-6039

Single-Command

Subroutine

L.ines 6500-6585

Position Repeatability Subroutine

Lines 7000-7486 converted to seconds by dividing by $F R$; this new rumber is printed on the PET screen.

The subroutine to position the source at storage sends a command $(C=3)$ to the SMC to position the source at the storage sensor. The positioning time TR measured with the jiffy clock is converted to seconds and is printed on the PET screen.

The single-command subroutine allows you to select one of the ten possible control commands (see p. 14) and send it to the communications subroutine for transmittal to the Shuffler.

The position repeatability subroutine runs sourcepositioning cycles to measure the repeatability precision at the irradiation position. Delays at code lines 7010,7047, 7065, and 7131 are used to slow the motor down and ensure that each step is complete before the next step is commanded by the computer. These delays ensure that an accurate count of steps is obtained beti in the irradiation transfer position and the forward overtrave1 sensor.

Communications

Subroutine

Lines $7900-8525$
The communications subroutine performs synchronization and message transmittal between the PET and the SMC. The PET jiffy clock is used to determine a maximum response time between messages during the communications sequence, ensuring that the PE? is not left waiting for a response if the SMC develops a problem. A detailed description of the 
Communications

Subroutine

(cont)

Read MOUSE Inputs

Subroutine

Lines 9000-9090 communications code is provided in Appendix $D$. This subroutine handles all communications with the SMC, provides error messages if the SMC detects a problem, and resets the SMC software if the maximum time for a message response is exceeded.

The subroutine to read MOUSE inputs reads the high and low (I2 and If in the code) bytes of the MOUSE input lines. The high byte is converted to variables representing the source position ( $R, S$, and $F)$ sensors, the stepping motor power $(P)$, the last command received from the Shuffler (I), and the Shuffler error (E) condition.

The subroutine to read MOUSE outputs reads the high and low (02 and 01 in the code) bytes on the MOUSE output lines. The high byte is converted and masked to obtain the last command $(0)$ that the PET sent to the SMC module.

The subroutine to set MOUSE outputs sets the high and $10 \mathrm{w}(02=\mathrm{S} 2$ and $01=\mathrm{S} 1$ in the code) bytes of the MOUSE output lines. Before calling this subroutine, use the subroutine to read the MOUSE output lines to obtain the low byte. This byte is not used in the communications. Instead, the low byte should be sent to the output lines to keep these lines from being altered. The high byte is established by adding the value 16 to the variable (C). This procedure ensures that the 
Set MOUSE Outputs

Subroutine

(cont)

Shuffler Restart

Subroutine

Lines 9400-9494 nonmaskable interrupt (NMI in the code) line of the SMC module is maintained high. If the line were set low, the SMC software would be reset.

The subroutine to restart the Shuffler sets the NMI line of the SMC high, then low, and then high again to cause an interrupt at the Motorola computer that resets the SMC and initializes the software. The MOUSE module is also reset. A reset may be necessary when communications synchronization is lost or when some other problem occurs with the SMC or the MOUSE.

NOTE: The SMC can also be reset by manually depressing the red button on the front panel.

MOUSE Control

Subroutine

Lines 9600-10000
The MOUSE control section of the code contains subroutines to operate and control the MOUSE module to perform scaler operation, timing, and other tasks. Descriptions of the operational commands and their meanings are provided in the Harwel1 MOUSE Users Guide(AERE-R 9463). 


\section{DESCRIPTION}

CALIFORNIUM-252

SHUFFLER SOURCE

\section{CABLE ATTACHMENT}

Cal ifornium-252 is a spontaneous fission neutron emitter. It has a 2.646-yr half-7ife, emits 2.34 $\times 10^{12} \mathrm{n} / \mathrm{s} / \mathrm{g}$, is a reliable source of neutrons, and can be packaged in a small container.

The Shuffler is designed to use a ${ }^{252} \mathrm{Cf}$ source encapsulated in a spccial package designed by Savannah River Laboratories, the SR-CF-100 package. The first source supplied for the Shuffler was loaned by Savannah River Laboratories. It contained $2.892 \mathrm{mg}$ of ${ }^{252} \mathrm{Cf}$, emitting $6.69 \mathrm{X}$ $10^{9} \mathrm{n} / \mathrm{s}$. This source emits a large quantity of radiation and must be shielded and handled with care.

The Shuffler operates by moving the ${ }^{252} \mathrm{Cf}$ source between the storage and irradiation positions. The source is attached to a Teleflex cable, and the cable is moved using a gear wheel controlled by a stepping motor. Figure A-1 shows the configuration of the cable bushing attachment. The source is securely held to the coupler bushing by set screws and Loctite.

\section{SHIPMENT}

SHIPPING CASK
The source is shipped in Atkinson Steel Company Cask \#127. This cask is certified to transport 


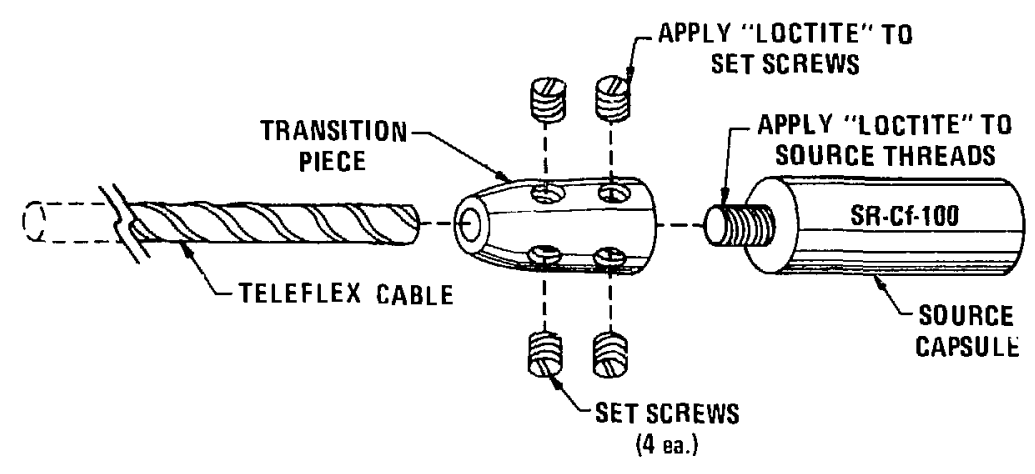

Fig. A-1. Cable bushing attachment.

SHIPPING CASK

(cont)

PRACTICE WITH

DUMWY SOURCE

PROCEDURE up to $2 \mathrm{Ci}(3.75 \mathrm{mg})$ of ${ }^{252} \mathrm{Cf}$. The cask requires a special insert (see Fig. A-2) for the source to be shipped with the Teleflex cable attached to it.

\section{SOURCE TRANSFERS}

A dummy source and Teleflex cable sent should be used to practice transfers until the procedure is well established.

The transfer procedure requires the following general steps:

1. Run the NDA5TST program and move the source to the irradiation position using the menu command U. Manually switch the stepping motor power supply off. 


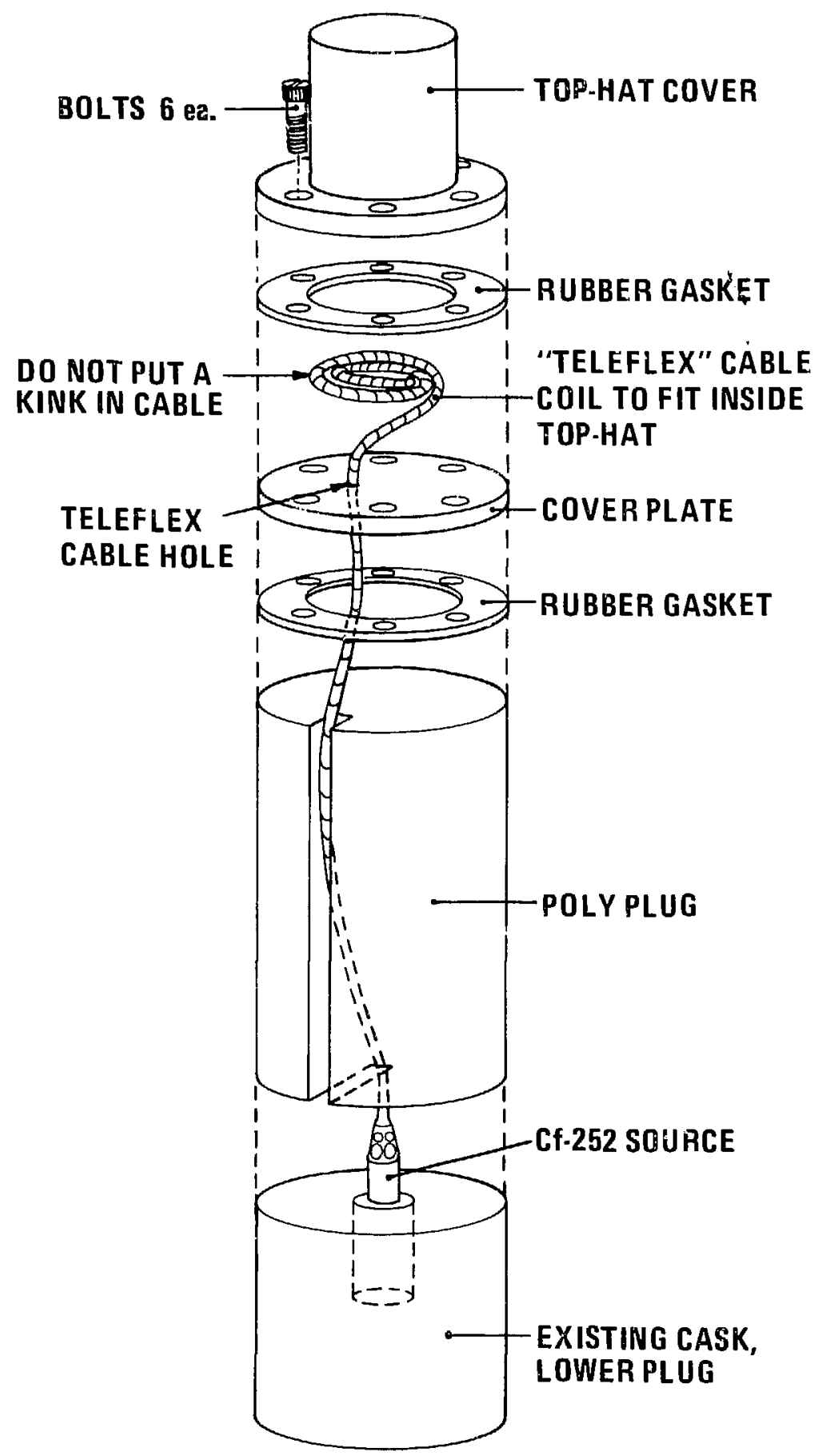

Fig. A-2. Shipping cask insert. 
PROCEDURE

(cont)
2. Unbolt the stepping motor, remove the Swagelok connections on the Teleflex cable takeup tube, and dismount the motor and tube.

CAUTION: Be careful that the cable does not come out of the tube if a live source is attached to it.

3. Keeping the cable all the way in the instrument, slowly remove the source keeper tube from the Shuffler.

4. Slowly remove the Teleflex cable and quickly place the old source in a large shield. (Remember, it is a strong radiation source.)

5. Remove the new source from its shield and quickly insert it fully into the Shuffler. F. $\therefore$ light machine oil on the Teleflex cable.

6. Replace the source keeper tube in the instrument.

7. Run the end of the Teleflex cable through the stepping motor gear box and into the Teleflex tube. Bolt the motor and tube onto the Shuffler assembly. 
PROCEDURE

(cont)
8. After you securely bolt the assembly, rotate the stepping wotor gear wheel by hand to ensure that the cable and source move easily in the Shuffler.

9. Switch on the stepping motor power supply and test slow movement of the source using the $U$ and $B$ options in program NDA5TST. If the system appears to operate properly, use the I and $S$ options to test fast movement of the source. If this test is successful, : ie the A option to test the overall assay capability of the Shuffler.

10. Load the Shuffler assay program, recalibrate the instrument, and continue with assay measurements using the new source. 


\section{CONTROL ELECTRONICS}

IRRADIATION SOURCE POSITION ADJUSTMENT

SWITCH SETTINGS
The side panel view of the SMC module is shown in Fig. B-1. An eight-position rocker switch on the side panel adjusts the irradiation source position. Switch positions 1 through 7 represent the number of binary steps to adjust the source position. Switch position 8 represents adding or subtracting an adjustment number to the fixed position (1244 steps) value in ROM. Twenty-five motor steps will move the source a distance of one inch.

The OFF setting on the switch is an open position producing a set (1) value and the $O N$ setting grounds the switch, producing a clear (0) value.

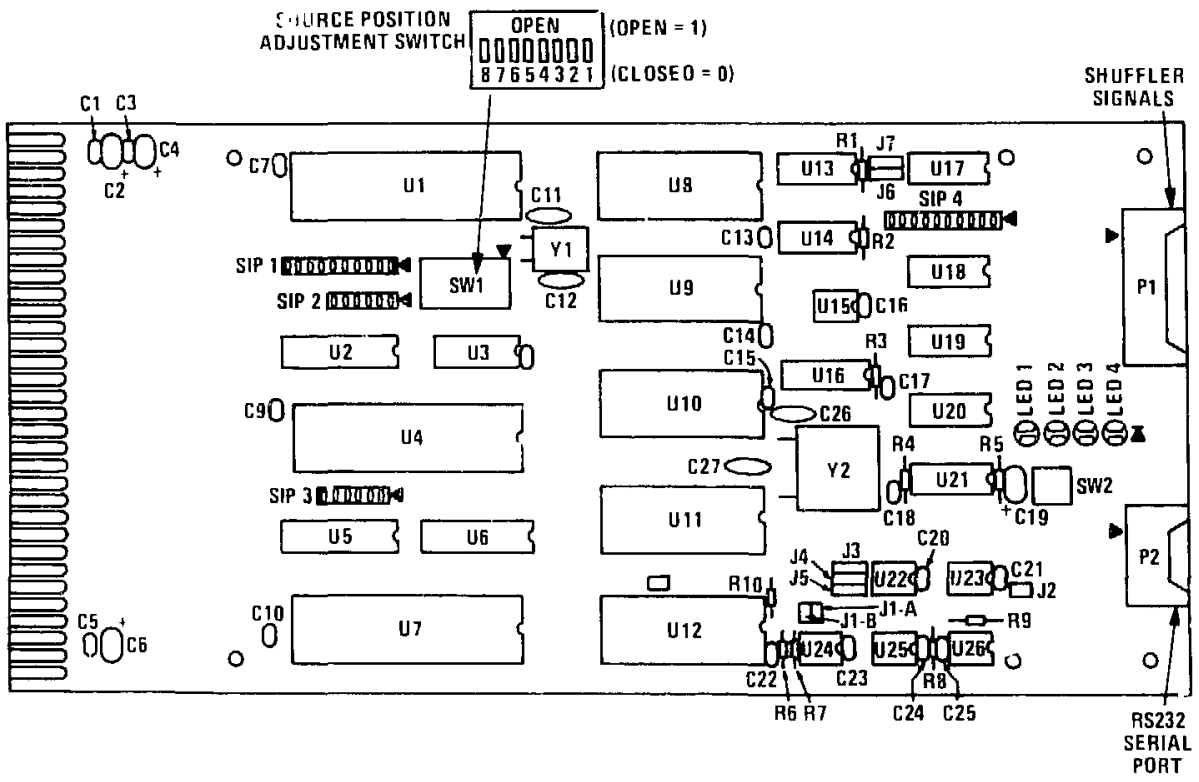

Fig. B-1. Side view of the SMC module. 
Add 12 Steps

St: :ract 12 Steps

SIGNAL LINES

MOUSE INPUT/OUTPUT LINES

Ou+put Lines
To add 12 decimal ( 14 octal) steps to the irradiation position, put switch 8 in the OFF position. Assign an octal value of 14 to switch positions 1 through 7 by putting switches 3 and 4 in the OFF position and switches $1,2,5,6$, and 7 in the ON position. This setting will now move the source 1256 steps from storage to irradiation.

To subtract 12 decimal (14 octal) steps from the irradiation position, put switch 8 in the ON position. Assign an octal value of 14 to switch positions 1 through 7 by putting switches 3 and 4 in the OFF position and switches $1,2,5,6$, and 7 in the on position. This setting will now move the source 1232 steps from storage to irradiation.

Signal and message lines between the SMC and MOUSE modules and the Shuffler are shown in Fig. B-2.

The MOUSE has 16 input and 16 output lines numbered from 0 to 15 . The high bytes ( 8 through 15) of the lines are used for PET-to-SMC communications. The bit designations are given below.

The output lines (OUTO through OUT15) convey messages sent from the PET to the IMC moduie. The bit definitions are as follows:

PET command (OUT8, OUT9, OUT10, OUT11) Restart the SMC module (OUTT2) 


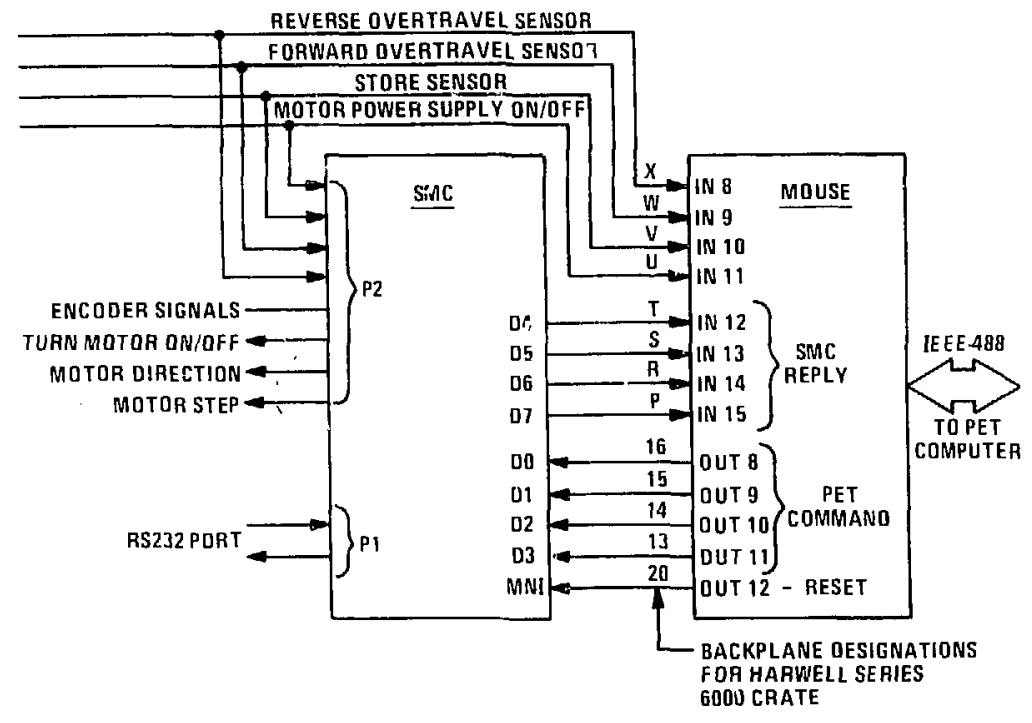

Fig. B-2. Signal lines for the SMC module.

Input Lines

The input lines (IN0 through IN15) convey messages sent from the SMC module to the PET. The bit definitions are as follows:

Reverse over-travel sensor (IN8)

Forward over-travel sensor (IN9)

Store sensor

Power on/off

SMC message

(IN12, IN1 3, IN14, IN15)

Signals between the SMC module and the Shuffler are routed through a distribution box. Wiring an signal definitions for the box are listed in Tables B-1 through B-IV. 
TABLE B-1

SMC RIBBON CABLE TO ENCODER CABLE

\begin{tabular}{|c|c|c|c|c|c|}
\hline $\begin{array}{l}\text { J1 } \\
\text { PIN }\end{array}$ & $\begin{array}{l}\mathrm{J} 4 \\
\text { PIN }\end{array}$ & $\begin{array}{l}\text { WIRE } \\
\text { COLOR }\end{array}$ & CONNECTOR & $\begin{array}{l}\text { WIRE } \\
\text { COLOR }\end{array}$ & $\begin{array}{l}\text { ENCODER } \\
\text { SIGNAL } \\
\text { FUNCTION }\end{array}$ \\
\hline 1ר 40 & $\begin{array}{l}1 \\
2 \\
3 \\
4 \\
5 \\
6\end{array}$ & $\begin{array}{l}\text { BLACK } \\
\text { RED } \\
\text { WHITE } \\
\text { GREEN } \\
\text { BLUE } \\
\text { ORANGE }\end{array}$ & $\begin{array}{l}\text { A } \\
\text { B } \\
\text { C } \\
\text { D } \\
\text { E } \\
\text { F }\end{array}$ & $\begin{array}{l}\text { BLACK } \\
\text { RED } \\
\text { WHITE } \\
\text { GRN/PUR } \\
\text { BLUE } \\
\text { ORANGE }\end{array}$ & $\begin{array}{l}\text { B } \\
+5 \text { VOLTS } \\
\text { A } \\
\text { GROUND } \\
\text { A } \\
\text { B }\end{array}$ \\
\hline
\end{tabular}

TABLE B-I I

SMC RIBBCN CABLE TO STEPPING MOTOR DRIVER CABLE

\begin{tabular}{|c|c|c|c|c|}
\hline $\begin{array}{l}\text { J1 } \\
\text { PIN }\end{array}$ & $\begin{array}{l}\text { J3 } \\
\text { PIN }\end{array}$ & $\begin{array}{l}\text { WIRE } \\
\text { COLOR }\end{array}$ & $\begin{array}{l}\text { SIGMA } \\
\text { DRIVER }\end{array}$ & $\begin{array}{l}\text { SIGMA DRIVER } \\
\text { FUNCTION }\end{array}$ \\
\hline $\begin{array}{l}5 \\
6 \\
7 \\
8 \\
16\end{array}$ & $\begin{array}{l}1 \\
2 \\
3 \\
4 \\
5\end{array}$ & $\begin{array}{l}\text { WHITE } \\
\text { SHIELD } \\
\text { GREEN } \\
\text { BLACK } \\
\text { RED }\end{array}$ & $\begin{array}{r}10 \\
8 \\
7 \\
4 \\
6\end{array}$ & $\begin{array}{l}\text { BSTEP } \\
\text { GROUND } \\
\text { BDIR } \\
\text { MOTOR } \\
\text { +5 VOLTS }\end{array}$ \\
\hline
\end{tabular}

TABLE B-II I

SMC RIBBON CABLE TO SENSOR CABLE

\begin{tabular}{|c|c|c|c|c|c|}
\hline $\begin{array}{l}\text { JI } \\
\text { PIN }\end{array}$ & $\begin{array}{l}J 2 \\
\text { PIN }\end{array}$ & $\begin{array}{l}\text { WIRE } \\
\text { COLOR }\end{array}$ & CONNECTOR & $\begin{array}{l}\text { WIRE } \\
\text { COLOR }\end{array}$ & $\begin{array}{l}\text { SENSOR } \\
\text { FUNCTION }\end{array}$ \\
\hline 0 & 1 & WHITE & 1 & WHITE & $\begin{array}{l}\text { REV OVER- } \\
\text { TRAVEL }\end{array}$ \\
\hline & 2 & GREEN & 2 & WHITE & $\begin{array}{l}\text { FWD DVER - } \\
\text { TRAVEL }\end{array}$ \\
\hline 12 & $\begin{array}{l}3 \\
4 \\
5\end{array}$ & $\begin{array}{l}\text { RED } \\
\text { SHIELD } \\
\text { BLACK }\end{array}$ & $\begin{array}{l}3 \\
4 \\
5\end{array}$ & $\begin{array}{l}\text { RED } \\
\text { BLACK } \\
\text { WHITE }\end{array}$ & $\begin{array}{l}+12 \text { VOLTS } \\
\text { GROUND } \\
\text { STORE }\end{array}$ \\
\hline
\end{tabular}


TABLE B-IV

STEPPING MOTOR DRIVER WIRING CONNECTIONS

POHER SUPPLY HIRING

Changing Wiring to $240 \mathrm{Vac}$

Changing Wiring to $120 \mathrm{Vac}$
The power supply of the stepping motor can be wired to operate from 120 or $240 \mathrm{Vac}$. The unit is initially configured to operate from $120 \mathrm{Vac}$.

To change the wiring from $120 \mathrm{Vac}$ to $240 \mathrm{Vac}$, follow the steps below and refer to the wiring diagram shown in Fig. B-3.

1. Move the ac line from strip position No. 2 to No. 4.

2. Remove the jumper between strip position No. 1 and No. 3.

3. Remove the jumper between strip position No. 2 and No. 4.

4. Insert a jumper between strip position No. 2 and No. 3.

To change the wiring back to $120 \mathrm{Vac}$, leave the ac line on No. 4 and replace the jumpers that were removed in the above steps. See Fig. B-4. 


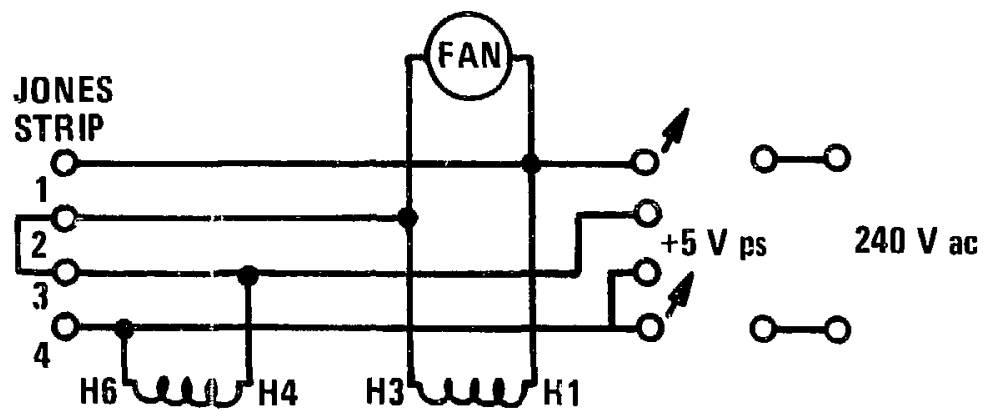

TRANSFORMER

Fig. B-3. 240 Vac wiring drawing

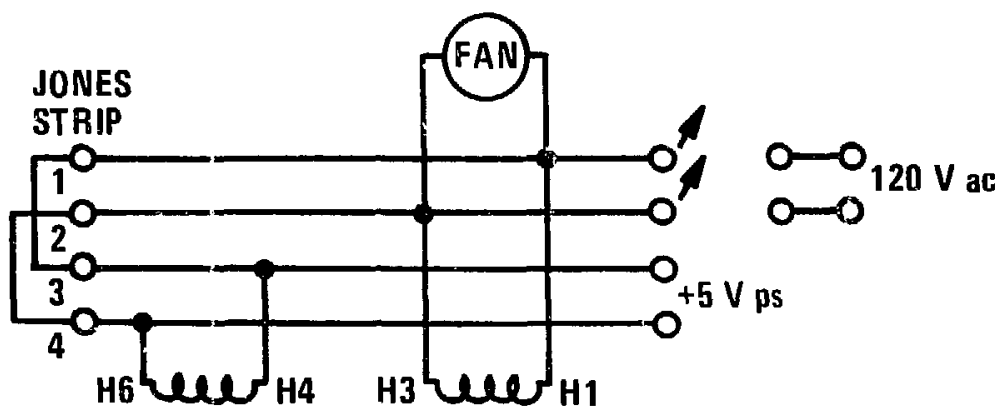

TRANSFORMER

Fig. B-4. 120 Vac wiring drawing

\section{SCHEMATICS AND COMERCIAL COMHONENTS}

ELECTRICAL SCHEMATIC

MECHANICAL SCHEMATICS
A foldout electrical schematic (Los A1amos Drawing No. 68Y-155671) for the Dounreay Shuffler SML: module is included as Fig. B-5.

The mechanical design and fabrication drawings of the Dounreay Shuffler unit are contained in L.os Alamos National Laboratory drawings 68Y-155466 01 through D15. These drawings are not included 
(1) FOR 4636 GND: PIN $4,+12 V=$ PIN O, - RVIIPWS

(5) UIT IS NOT USED IN THLS ATPLKATION

(1) FOR 9635 , GND. PIN 4, +ITV.PIN

2. XTAL LATOUT-SEAT XTALS ON GanO PLANE VITH

SHORT RUWE TO LEADS. NO CIRCLUITRY UNDER LEADS.

(3) INSTALL NOK PLLUP RESISTURS ON PBQ - PBSISIP 3 )

4 DOUNREAT CARD FINGERS - NUMBERS ON FRONT, $L \equiv$ TTERS ON BWCK
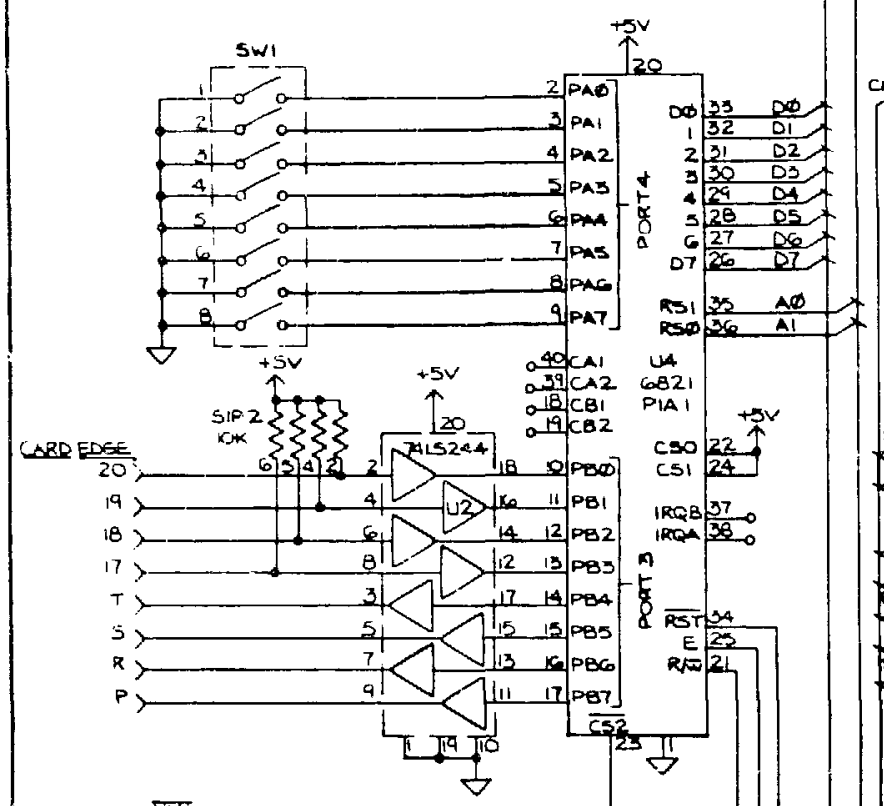

16. सMा

$\checkmark$

$\times$ BREOT

$U$ ᄀ CMKSMP

$\checkmark)$ STORE

P2

D-PIM BERS

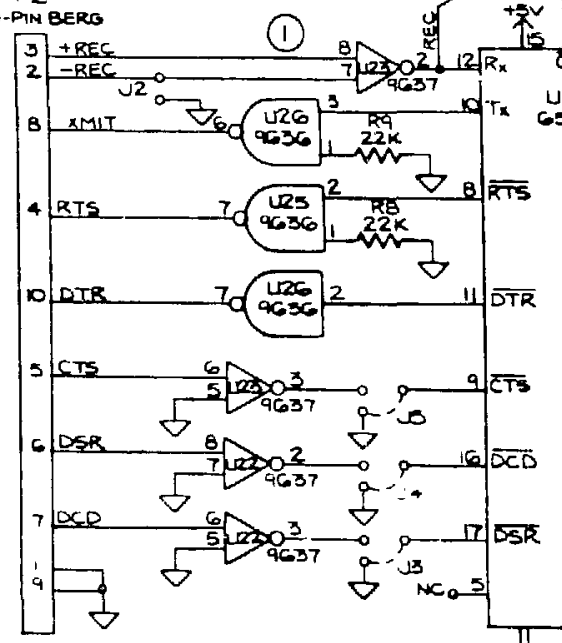

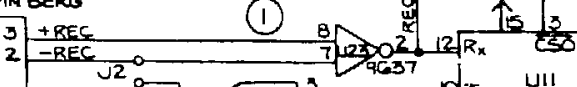

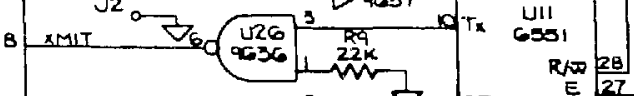

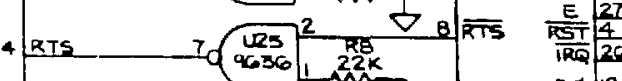

Dos 18

119

$2 \frac{20}{21} \quad D 2$

$3 \frac{21}{22}-\frac{D 3}{23}$

$422 \quad 24$

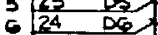

$07\left|\frac{24}{25} \cdot 07\right|$

$\operatorname{Ros} \mid \begin{array}{lll}13 & A & A \\ 14 & A !\end{array}$

re27

6. I

(3)

ancar csore is

TFis

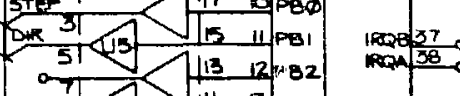

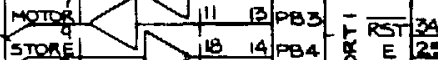

Fuont

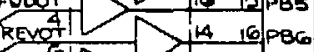

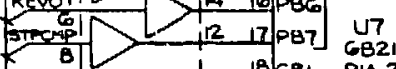
TIA TIO

ह53

$\int^{23} \sqrt{1}$

\section{2!}

- 1 लस
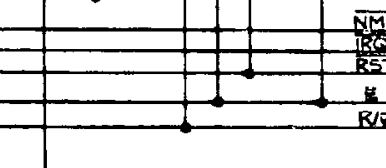

Q.
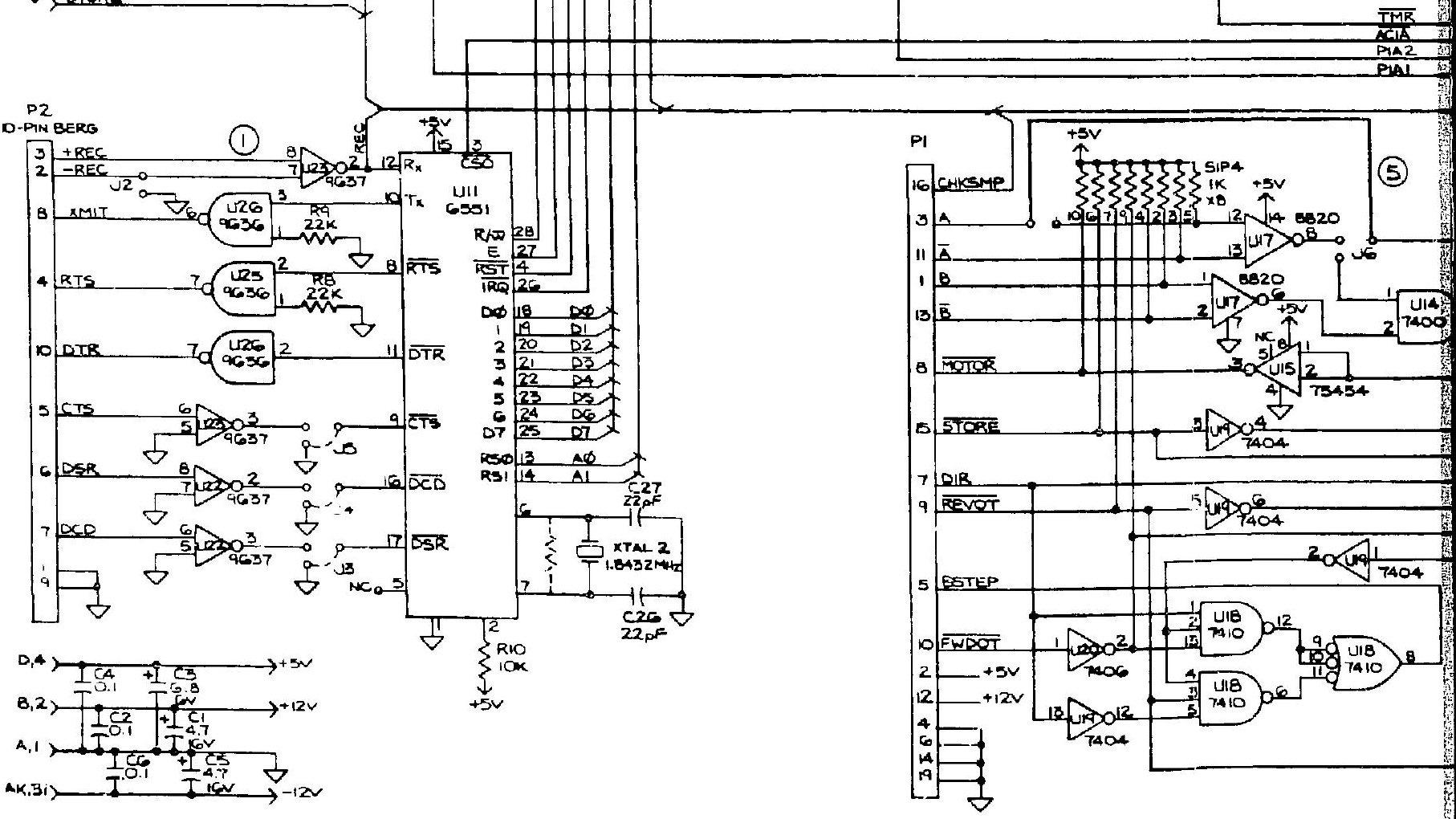

Fig. B-5. SMC electronic schemat 


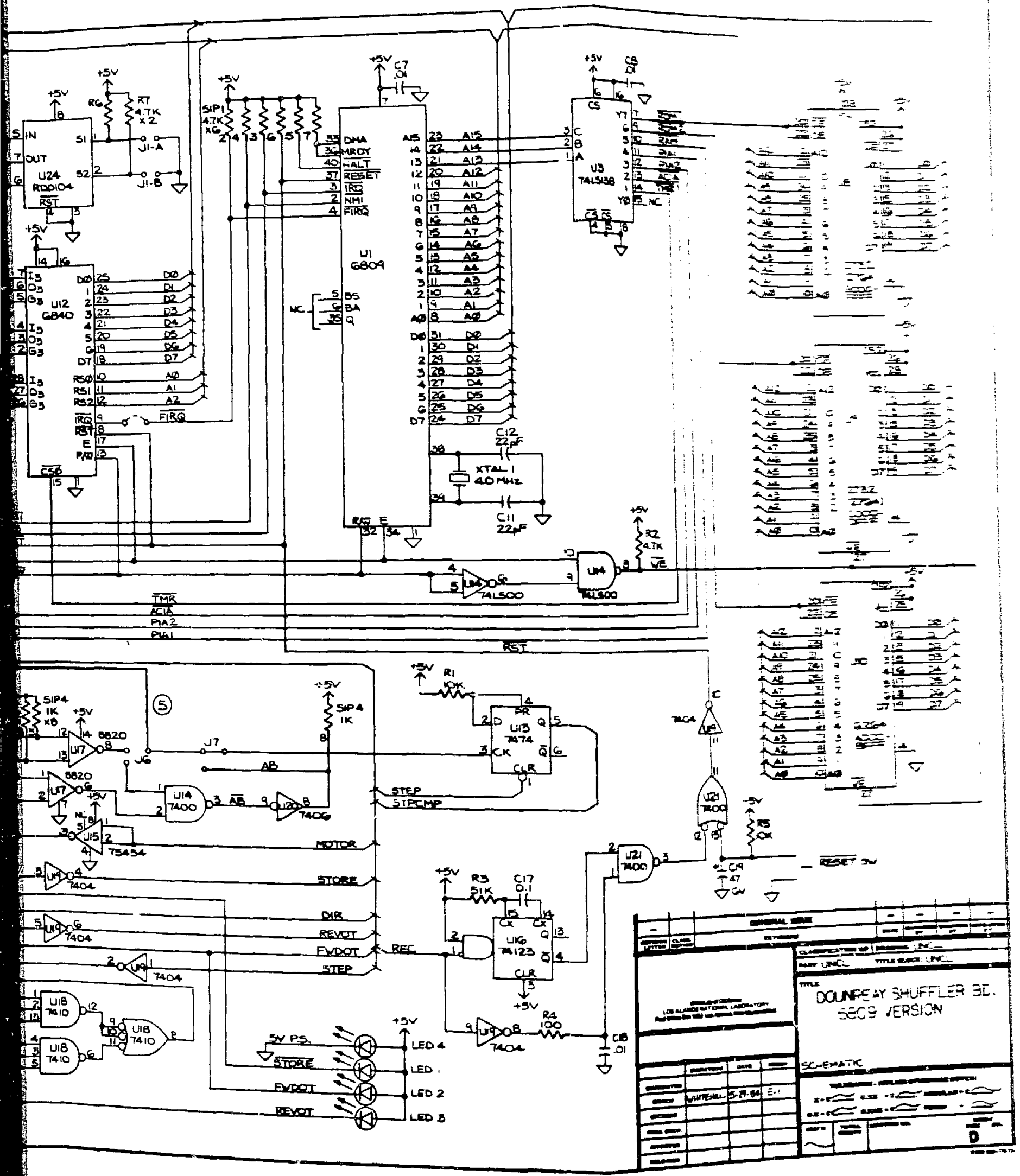

lectronic schematic. 
MECHAHICAL SCHEMATICS

(cont)

COMMERCIAL EQUIPMENT with this manual. They are on file at both Los Alamos and the Dounreay facility.

Several items composing the Shuffler were obtained from commercial sources. Table $B-V$ shows the commercial items.

TABLE B-V

COMMERCIAL COMPONENTS USED IN SHUFFLER

\begin{tabular}{llll}
\multicolumn{1}{c}{ Item } & Model Number & \multicolumn{2}{c}{ Manufacturer } \\
\cline { 1 - 1 } Proximity Sensors & FYAA3A1-2 & & Micro Switch \\
Stepping Motor & $21-3450 D-23821$ & Sigma Instruments, Inc. \\
Encoder & A236-12 & Datametrics, Inc. \\
Motor Power Supply & $29 B-16-105$ & Sigma Instruments, Inc.
\end{tabular}


ERROR MESSAGE EXPLANATION

Error No. 11: Invalid Command Sent by

PET Computer

Error No. 12: Check Sensors, Power Supply, and Motor Status

Error No. 13:

Over-Travel Sensor Failed to Stop Steps
The five possible error messages from the Shuffler SMC module are listed below with explanations of possible causes and corrections.

Error number 11 is on code line 8241. This error is produced when the PET computer sends a command outside the allowed range ( 0 through 10 ) to the SMC module.

Error number 12 is on code 1 ine 8242 . This message represents a general error condition. The stepping motor power supply may be off. The source could have been moved too far in either direction producing an over-travel sensor error.

Error number 13 is on code 1 ine 8243 . This error results if the hardware in the SMC module fails or if the over-travel sensor is not properly working. A sensor improperly seated cannot reliably sense a blocked condition. A malfunctioning sensor is indicated if a source movement results in the maximum allowable number of steps occurring without an over-travel signal being generated. Use the $T$ option in program NDA5TST to check operation of the cable position sensors.

Error No. 14: Encoder Failed to Provide Step-Completion Signal
Error number 14 is on code 1 ine 8244 . The SMC module monitors the stepping motcr encoder for a step-complete pulse each time the motor takes a step. This error results if the stepping motor encoder fails or if an over-travel sensor has been activated, and stops the motor from taking steps. 
Error No. 14: Encoder Occasional errors nct involving over-travel sen-

Failed to Provide sors indicate that the encoder should be reaStep-Completion Signal ligned.

(cont)

Error No. 15: Encoder Error number 15 is on code 1 ine 8245. This error Provided Excess Step- results when a step-complete signal is produced Completion Signal and the SMC module did not issue a step pulse. This error generally occurs if noise is being generated on the signal cables. 


\section{PET-TO-SHUFFLER COMMUNICATIONS}

PET-TO-SHUFFLER

MESSAGE FORMAT

PET MESSAGES

SMC MESSAGES

MESSAGE

SYMCHRONIZATION
The PET computer and the SMC module communicate through a simple handshake sequence.

The PET initiates all communications with the SMC and sends commands on bits $8,9,10$, and 11 of the high byte of the MOUSE output lines. PET messages are denoted in the code by the variable 0 (letter " 0 "), and the value ranges from 0 (zero) to 15. Table D-I shows the message numbers and their meanings. Bit 12 of the MOUSE output line is wired to the microprocessor of the NMI port of the SMC. This bit must be held high to prevent interrupts occurring that would reset the SMIC.

The SMC waits for commands from the PET computer and sends reply messages to the PET on bits 12, 13,14 , and 15 of the high byte of the MOUSE input lines. SMC messages are denoted in the code by the variable $I$ and the values range from 0 (zero) to 15. Table D-I shows the message numbers and their meanings.

Messages between the PET and the SMC follow the set of synchronized steps shown in Table D-II. 
TABLE D-I

PET AND SMC MESSAGES

\begin{tabular}{|c|c|c|}
\hline $\begin{array}{l}\text { MESSAGE } \\
\text { NUMBER }\end{array}$ & $\begin{array}{c}\text { PET } \\
\text { COMMAND } \\
(0) \\
\end{array}$ & $\begin{array}{c}\text { SMC } \\
\text { REPLY } \\
(I) \\
\end{array}$ \\
\hline 0 & Request completion signal & Busy \\
\hline 1 & Turn motor on & Motor turned on \\
\hline 2 & Turn motor off & Motor turned off \\
\hline 3 & Position source at storage & Source positioned at storage \\
\hline 4 & Move source to irradiate & Source at irradiate \\
\hline 5 & Move source to storage & Source at storage \\
\hline 6 & Block sensors & Sensors blocked \\
\hline 7 & Unblock sensors & Sensors unblocked \\
\hline 8 & Set direction to irradiate & Direction set to irradiate \\
\hline 9 & Set direction to storage & Direction set to storage \\
\hline 10 & Take one step & One step taken \\
\hline 11 & none & Error message 11 \\
\hline 12 & none & Error message 12 \\
\hline 13 & none & Error message 13 \\
\hline 14 & none & Error message 14 \\
\hline 15 & none & Error message 15 \\
\hline
\end{tabular}

TABLE D-II

SYNCHRONIZED STEPS FOR COMMANDS BETWEEN PET AND SMC

\begin{tabular}{cl}
$\begin{array}{c}\text { MESSAGE } \\
\text { STEP }\end{array}$ & \multicolumn{1}{c}{$\begin{array}{c}\text { PET } \\
\text { COMMAND }\end{array}$} \\
1. & Wait for SMC ready. \\
2. $\quad \begin{array}{l}\text { Send variable } C \text {. Wait unti 1 } \\
\text { SMC receives command and sends } \\
\text { a zero indicating acceptance. }\end{array}$ \\
3. $\quad \begin{array}{l}\text { Request command completion } \\
\text { signal by sending zero. }\end{array}$ \\
4. Wait for SMC completion signal.
\end{tabular}


COMMAND PROCESSING

\section{COMMUNICATIONS EXAMPLE}

Communication

Subroutines
While the SMC is processing a command, its message number is set to zero. After the SMC completes a command and receives a completion signal request

(0) from the PET, it will

1) Echo the command number if completed successfully, or

2) Send an error message number if a problen occurred.

A sample communications code is shown in Table D-III. The PET BASIC code that implements communications with the SMC is explained below, using the sample. Variables used in this example and throughout the BASIC code (NDA5TST) are described in Table D-IV. Please refer to the NDA5TST program listing in Appendix $E$ for a complete example of the communication code.

Three subroutines are called from the communications code. Refer to the examples of MOUSE communications at the end of this appendix for complete details of these subroutines. The subroutines perform the following functions:

Subroutine 9000: Reads the MOUSE input lines and converts the high byte (12) to the variable I to obtain the SMC message.

Subroutine 9100: Reads the MOUSE output lines to obtain the value of the low (01) output byte. 
TABLE D-III

SAMPLE COMMUNICATIONS CODE

LINE

8000

8010

8020

8030

8040

8045

8050

8060

8070

8080

$809 \mathrm{C}$

8100

8110

8120

8130

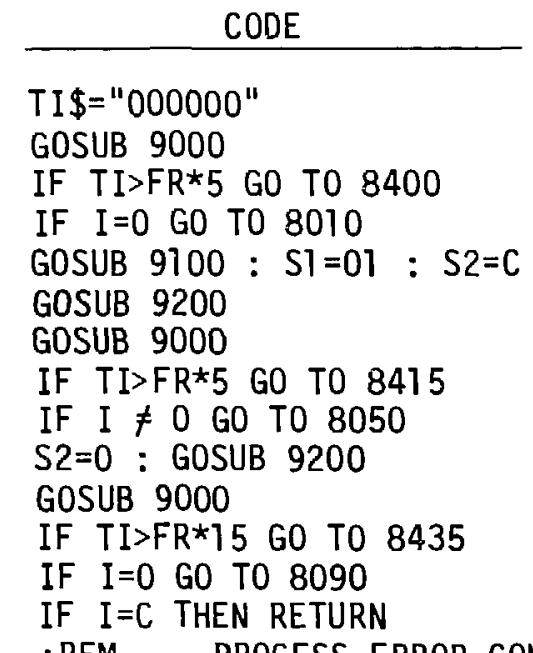

:REM $-2-$ PROCESS ER

PROCESS ERROR CONDITIONS

\begin{tabular}{l} 
REMARK \\
\hline :REM ZERO PET CLOCK \\
:REM GET SMC STATUS \\
:REM 5 SEC RESPONSE LIMIT \\
:REM WAIT FOR SMC READY \\
:REM SET UP OUTPUT LINES \\
:REM SEND COMMAND TO SMC \\
:REM GET SMC STATUS \\
: REM 5 SEC TIME LIMIT \\
:REM WAIT FOR SMC BUSY \\
:REM REQUEST COMPLETION SIGNAL \\
:REM GET SMC STATUS \\
:REM 15 SEC TIME LIMIT \\
:REM WAIT FOR COMPLETION SIGNAL \\
:REM COMPLETION OK \\
R S -
\end{tabular}

TABLE D-IV

PROGRAM VARIABLE DEFINITIONS

CODE

VARIABLE

DEF INITION

VALUES

$R \quad$ Reverse overtravel sensor

$F \quad$ Forward overtravel sensor

$S \quad$ Store sensor

P Motor power

D Source movement direction

$\begin{aligned} \text { E } & \text { Fatal error } \\ \text { EM } & \text { MOUSE error } \\ \text { EL } & \text { Error listing } \\ \text { ER } & \text { Error on repeatability test } \\ \text { ES } & \text { Error status } \\ \text { EC } & \text { MOUSE error code }\end{aligned}$

\begin{tabular}{|c|c|}
\hline \multicolumn{2}{|c|}{ VALUES } \\
\hline $\begin{array}{l}0=\text { unb } 1 \text { ocked } \\
0=\text { unbl ocked } \\
0=\text { unbl ocked } \\
0=\text { off } \\
8=\text { irradiate }\end{array}$ & $\begin{array}{l}1=\text { bl ocked } \\
1=\text { bl ocked } \\
1=\text { blocked } \\
1=\text { on } \\
9=\text { store }\end{array}$ \\
\hline $\begin{array}{l}0=\text { no } \\
0=n 0 \\
0=\text { yes } \\
0=\text { no } \\
0=10\end{array}$ & $\begin{aligned}-1 & =\text { yes } \\
-1 & =\text { yes } \\
1 & =\text { no } \\
-1 & =\text { yes } \\
-1 & =\text { yes }\end{aligned}$ \\
\hline
\end{tabular}


TABLE D-IV (cont)

PROGRAM VARIABLE DEF INITIONS

\begin{tabular}{|c|c|c|}
\hline $\begin{array}{c}\text { CODE } \\
\text { VARIABLE } \\
\end{array}$ & DEFINITION & VALUES \\
\hline 1 & Input to PET from SMC & $0-15$ \\
\hline 0 & Output from PET to SMC & $0-15$ \\
\hline $\mathrm{C}$ & Command to SMC & $0-10$ \\
\hline 01 & MOUSE output low byte & - \\
\hline 02 & MOUSE output high byte & - \\
\hline I1 & MOUSE input low byte & _- \\
\hline 12 & MOUSE input high byte & ـ \\
\hline S1 & MOUSE output 10 w byte & _ \\
\hline S2 & MOUSE output high byte & - \\
\hline TR & Transfer time $(s)$ & \\
\hline TI & Transfer time $(\mathrm{Hz} / ! 0)$ & \\
\hline TB & Background count time (s) & \\
\hline TO & Delay Time (ticks) & \\
\hline T1 & Transfer time from store to irradiate (s) & \\
\hline T2 & Irradiation time $(s)$ & \\
\hline T3 & Transfer time from irradiate to store $(\mathrm{s})$ & \\
\hline T4 & Delayed neutron count time (s) & \\
\hline T5 & MOUSE timer preset time $(s / 10)$ & \\
\hline $\mathrm{AO}$ & Assay cycle counter & \\
\hline A1 & Total number of assay cycles & \\
\hline A2 & Assay cycle output line counter & \\
\hline A3 & Assay cycle output line counter & \\
\hline $\mathrm{BC}$ & Background count rate (counts/s) & \\
\hline FM & Flux monitor count rate (counts/s) & \\
\hline DN & Delayed neutron count rate (counts/s) & \\
\hline FR & Frequency of PET clock $(\mathrm{Hz})$ & \\
\hline MU & $\begin{array}{l}\text { Mean number of steps to FWDOT sensor in } \\
\text { repeatability test }\end{array}$ & \\
\hline $\mathrm{S}$ & Standard deviation of steps in & \\
\hline & repeatability test & \\
\hline$X(M)$ & Trial number in repeatability test & \\
\hline & $\begin{array}{l}\text { Number of steps to FWDOT sensor in } \\
\text { repeatability test trial number } M\end{array}$ & \\
\hline $\mathrm{L}$ & Single step counter & \\
\hline $\mathbf{N}$ & Total number of trials in repeatability & \\
\hline NP & $\begin{array}{l}\text { test } \\
\text { Numer }\end{array}$ & \\
\hline NP & Number of blank lines to be printed & \\
\hline
\end{tabular}


Communication

Subroutines

(cont)

Sample Code Description
Subroutine 9200 : Sets the output lines of the MOUSE module. This subroutine adds 16 jo the high byte (S2) to ensure that the SMC interrupt line is held high.

Line 8000: Zeros the PET jiffy clock to monitor response timing.

Line 8010: Reads the MOUSE input 1 ines to obtain the SMC message status (I).

Line 8020: Transfers out of the communications subroutine if the SMC has not reached a ready state within $5 \mathrm{~s}$. The time is measured in hertz, and you need to know the line frequency (FR) to obtain the time in seconds. Line 8400 prints a timeout message on the PET screen. An interrupt to the SMC is then generated to reset the module; if the interrupt is successfu1, the PET program transfers to the main menu.

Line 8030: If the SMC is not ready, its message status equals zero $(I=0)$, and this line transfers the code back to the read SMC status line. 
Sample Code Description

(cont)
Line 8040: The SMC is ready for a command, so subroutine 9100 is called to obtain the low byte (01) on the MOUSE output lines. The low byte is set equal to S1. The high byte (S2) is set equal to the variable $C$.

Line 8045: Subroutine 9200 adds 16 to S2 and places $S 1$ and S2 on the MOLSE output 1 ines. S2 contains the control message for the SMC. Adding the number 16 keeps the SMC module interrupt line high to prevent a module reset.

Line 8050: Reads the MOUSE input lines to obtain I.

LINE 8060: Transfers out of the communications subroutine if the SMC has not sent a busy signal within $5 \mathrm{~s}$. Line 8415 prints a timeout message on the PET screen. An interrupt to the SMC is then generated to reset the unit, and, if the interrupt is successful, the PET program transfers to the main menu.

LINE 8070: If the SMC has not accepted the command, the variable I on the input line will be nonzero. Therefore, this line transfers the program to 1 ine 8050 , the read MOUSE input line. 
Sample code Description (cont)
Line 8080: The PET command has been accepted by the SMC. The PET requests a command completion signal from the SMC by setting the high byte to zero $(S 2=0)$ and calling subroutine 9200 to transmit it to the SMC. The low byte, S1, will not have changed from its initial value.

Line 8090: The PET reads the MOUSE input lines to obtain I.

Line 8100: Transfers out of the communications subroutine if the SMC has not provided a command completion signal within $15 \mathrm{~s}$. Line 8435 prints a timeout message on the PET screen. An interrupt to the SMC is then generated to reset the unit and, if the interrupt is successfu1, the PET program transfers to the main menu.

Line 8110: Checks for command completion by the SMC. If $I=0$ the SMC is busy processing the command, and the code loops back to the read status subroutine.

Line 8120: If the SMC status equals the command $(I=C)$, then the task was successfully completed, and the code returns to the calling program. Otherwise, I equals an error message number that appears on the PET screen. 
COMMUNICATION ERRORS

INTRODUCTION

CONYRT FROM ASCII

TO DEC IMAL
If a communication error occurs and message syrichronization is lost, the PET program will time out and reset the SMC module. The SMC then positions the source at storage and waits for a command from the PET. If the reset attempt is unsuccessful, the PET displays an error message to inform you of the problem. You should then do a manual reset by pushing the RESET button on the front panel of the SMC module.

\section{MOUSE COMMUNICATIONS}

The rET communirates with the SMC through the MOUSE using codes that must be converted between the MOUSE and the PET computer. This section describes the codes and subroutines for communications through the MOUSE.

The MOUSE input lines carry the signals from the SMC to the PET. The low byte in the code is desigriated by II and the high byte is designated by 12. The MOUSE output lines carry signals from the PET computer to the SMC.

The MOUSE module is designed to transmit and receive string data. The data received must be converted from the ASCII value to a decimal value before use by the PET code. An example of the code for conversion of the low byte (17\$) and high byte (I2\$) ASCII strings to the decimal values II and $: 2$ follows: 
CONYERT FROM ASCII

TO DECIMAL

(cont)

SMC Messages

$$
\begin{aligned}
& \text { II=0: IF I1\$ } \gg \text { " THEN I1=ASC (I1\$) } \\
& \text { I2=0: IF I2\$ } \ll " \text { THEN I2=ASC (I2\$) }
\end{aligned}
$$

Signals froin the SMC to the PET are transmitted on bits 12 through 15 of the high bute (I2) of the MOUSE input 1ines. Bit 12, an NMI iine used to reinitialize the SMC controller, should be held high to prevent reset interrupts from occurring. The following BASIC code shifts these SMC messages to values between 0 and 15 for interpretation by the PET:

$$
I=(I 2 \text { and } 240) / 16 \quad: \text { REM SMC message }=I
$$

The subroutine reads the 16 input lines on the Harwel1 MOUSE unit into the PET computer using the following PET BASIC code:

$\begin{array}{ll}\text { OPEN } 1,13,8 & \text { :REM Open IEEE port to read } \\ \text { PRINTH1,CHR } \$(0) & \text { :REM Set read to input line } \\ \text { GET\#1,I1\$,I2\$ } & \text { :REM Read high byte I } \$ \text { and } \\ & \text { low byte I1 } \$ \\ \text { CLOSE ? } & \text { :Release port. }\end{array}$

READ MOUSE OUTPUTS SUBROUTINE 9100

READ MOUSE INPUTS SUBROUTINE 9000 
READ MOUSE OUTPUTS

SUBROUTINE

(cont)
OPEN $1,13,8$

PRINT\#1,CHR \$(255)

GET\#1,02\$,01\$

CLOSE 1
:REM Open IEEE port to read

:REM Read output line

:REM Read bytes

:REM Release port
SEND COMMAND C SUBROUTINE 9200
SMC RESET

This subroutine sets the output lines of the MOUSE module. The code adds 16 to the high byte (S2) of the output line. This procedure ensures that the NMI line, bit 12, is kept high to prevent a reset or interrupt. The code required to send a command from the PET computer to the SMC module is as follows:

OPEN $1,13,7$

:REM Write to MOUSE PRINT\#1,CHR $\$(02+16), C H R \$(01)$ :REM Send command C CLOSE ?

The command to send an NMI to the SMC module uses bit 12 of the MOUSE output. The communications sequence is modified from the above discussion because the SMC initializes variables and restarts the program. If the restart is successful, the SMC module piaces a value of 8 on the comminications line. The PET computer should wait for this value to ensure the reset is successfut.

ADDITIONAL INFORMATION

Detailed information on the communication and control operations between the PET computer and MOUSE module is contained in the Harwell MOUSE Users Manual (AERE-R-9463). 


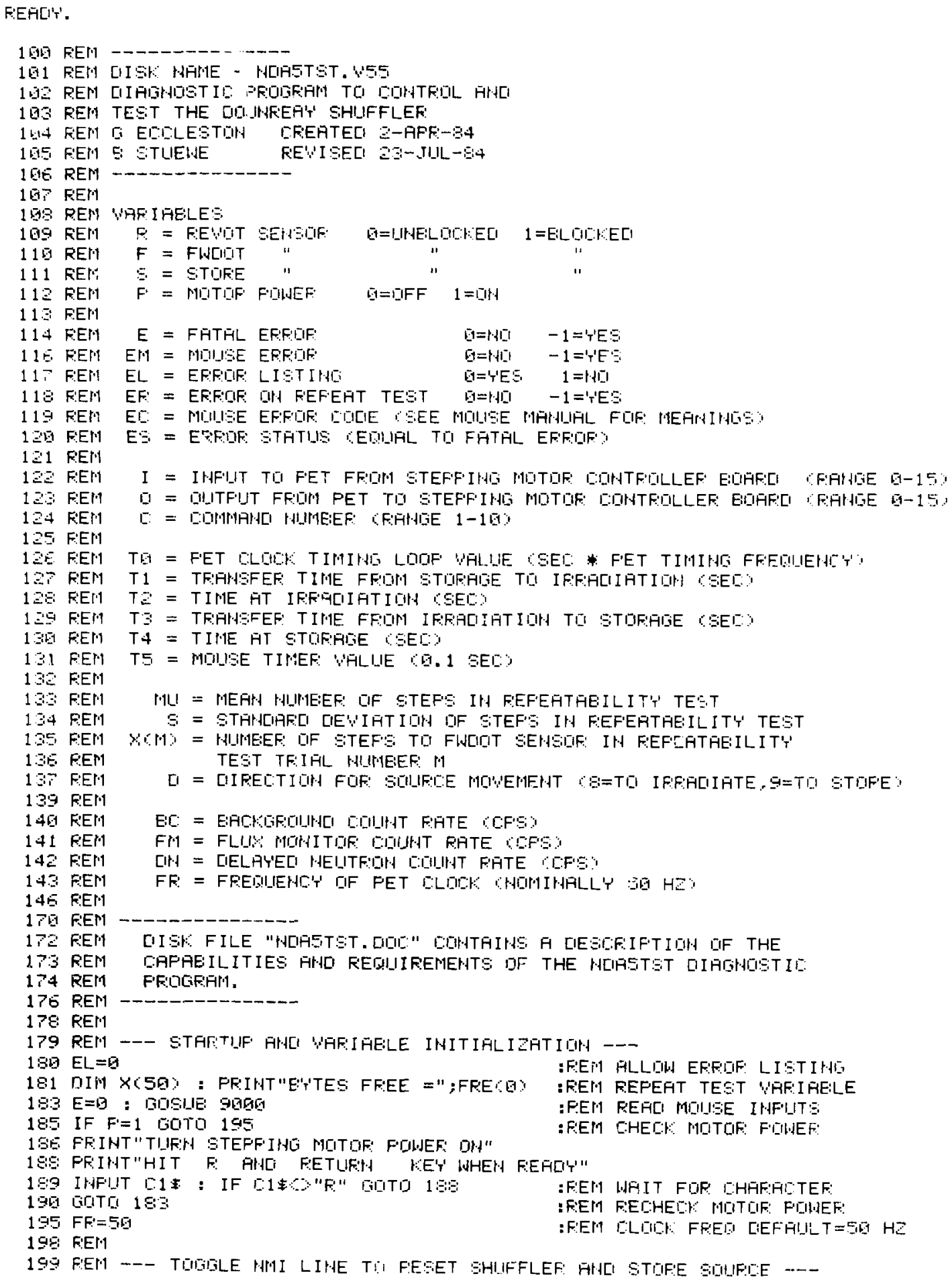




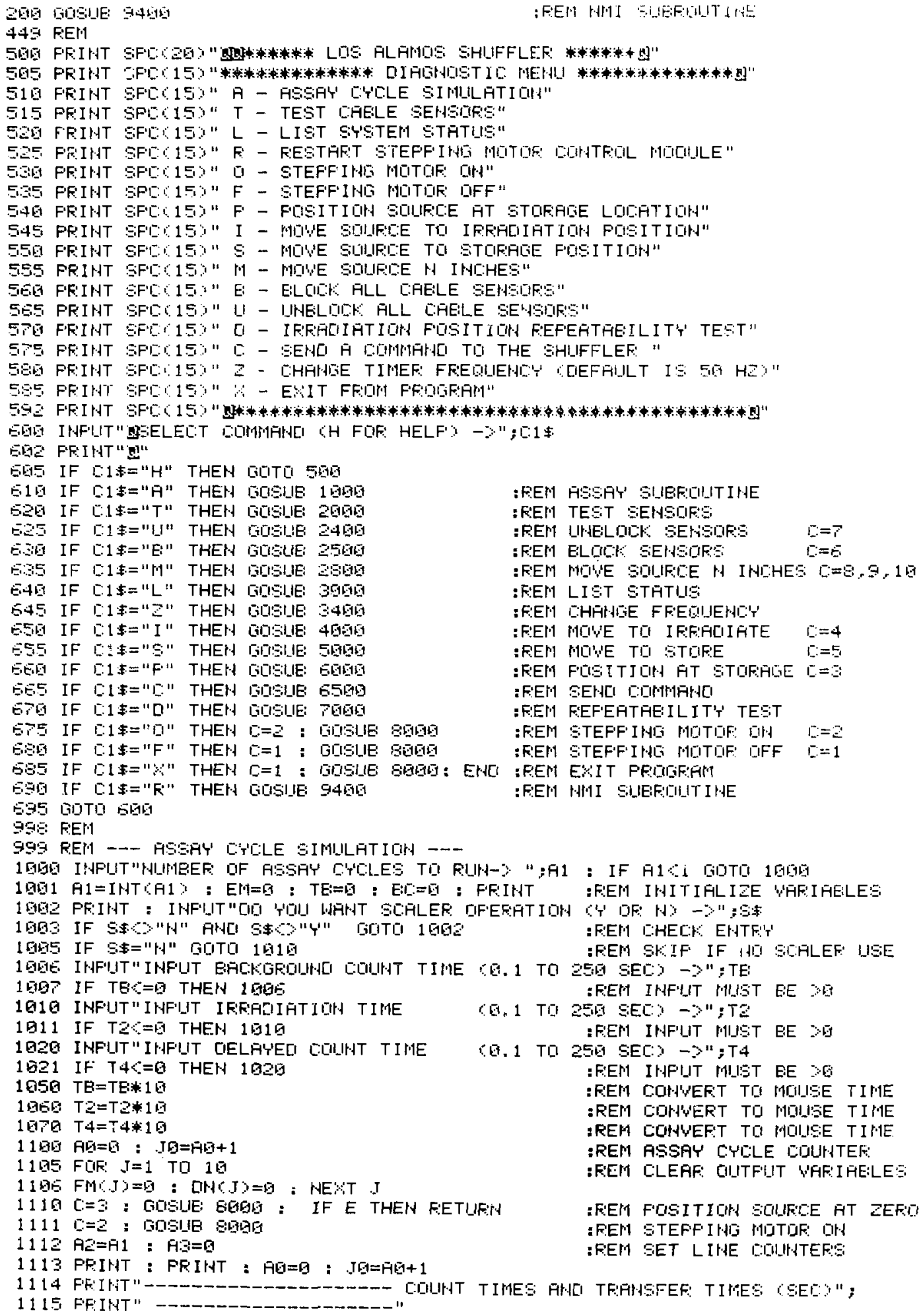
1114 FFIIH"

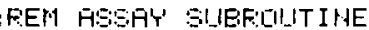
:E.EM TE:ST SEYHSIIES: 
111 F FF"

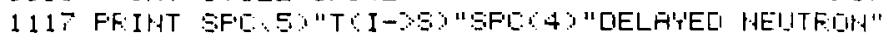

1118 FEM

1119 F:EM

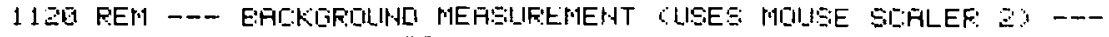

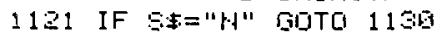

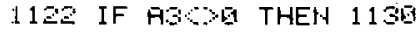

1123 GOGIJE: $\$ 1 \mathrm{E}$ : IF EM THEH FETUF'

1124 TS=TE: : GiLISILE GEABD

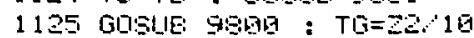

$112 \mathrm{E}$ IF TEA THEH 1125

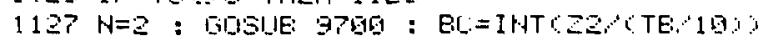
:FEH SUIF IF WI SIËLEF IIEE

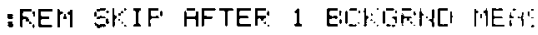
:FIER IF MOILES EFFIOIF Eri=:

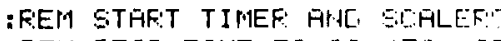

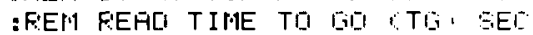

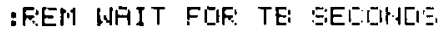

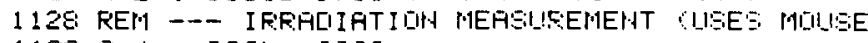
$1130 \mathrm{C}=4$ :

1140 T $1=$ T T I FF: $1 \mathrm{E}$

114: IF St="4" GiJTO 1151

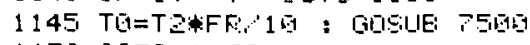

1156 BOTO $118 \mathrm{G}$

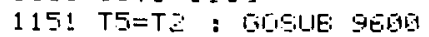

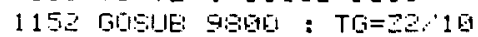

115 IF TGOA THEH $115 \mathrm{O}$

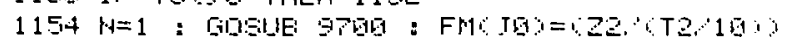

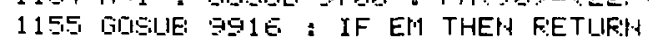

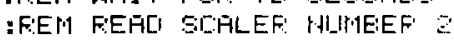

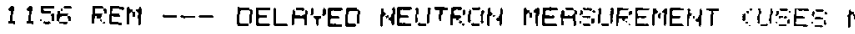

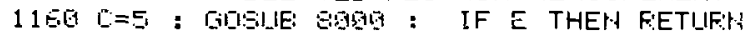

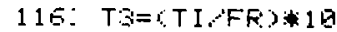

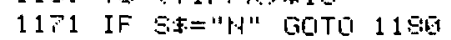

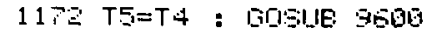

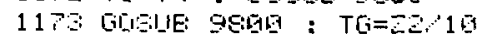

1174 IF TIOS THEH $117 \mathrm{O}$

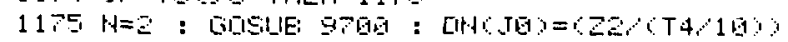

$117 \mathrm{E}$ GOILE:

$117 \vec{i}$ BiTा 1195

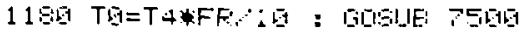

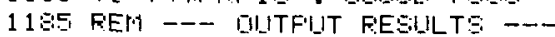

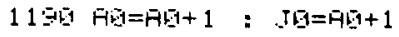

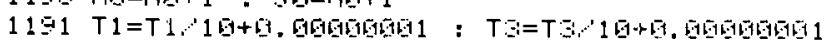

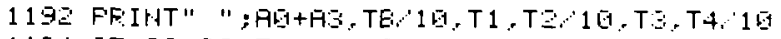

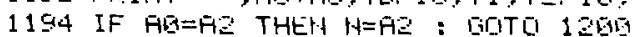

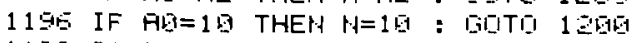

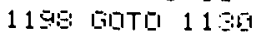

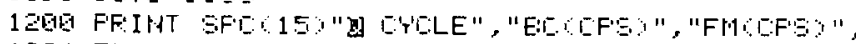

1204 FIIF: $T=1$ TOI H

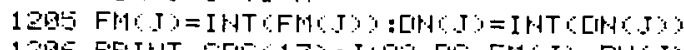

BIIFILEF' 1 y - -

:FEY1 NFF TO IFFECIITTE.

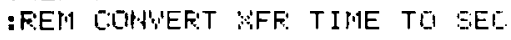

:FIEH SKIF IF SIELEF IISE

:FEN WHIT TZ SEL LISIHW FET ELE

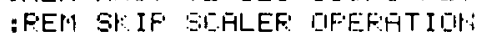

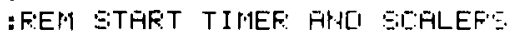

: FEM REALI TINE TOI TIO OTI

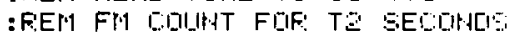

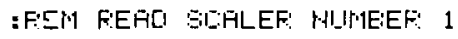

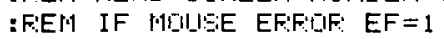

PIIISE SICALEF $\because$ :-

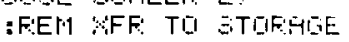

: FEA COIPUEFT YFF TIME TII EEL.

:FEH EYIF IF HII SIOALEF: II:E

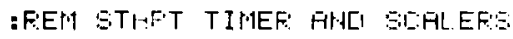

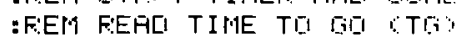

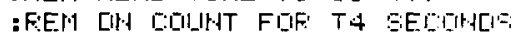

:F:EI1 F:ERLI SI:HLEF HIIIE:EF :

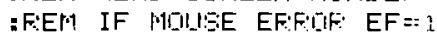

:FEM BVIF IF EILFLEF IISE

:FEV WIFIT TA EEL LISIHIS FET CLL

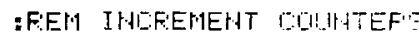

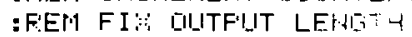

:FEM DIITFIIT TIME:

:PEIA SET \# DIF LIRES TO FFIIHT

: FEM SE DIF LIHES TI FFISTT

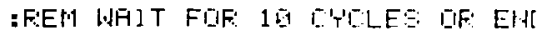

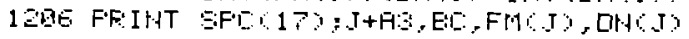

1:UG HEYT I

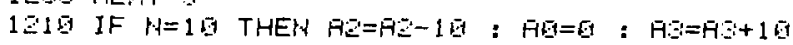

1212 IF AEAO THEH BOTIO 1113

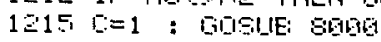

1220 PETUFH.

1996 REP

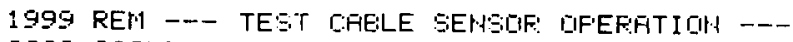

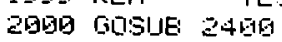

"CIPACF"E"

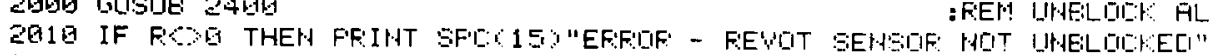

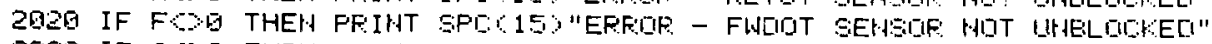

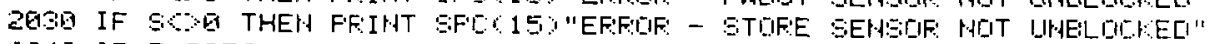

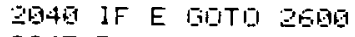

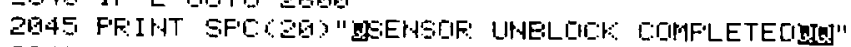

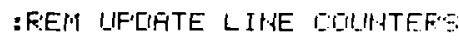

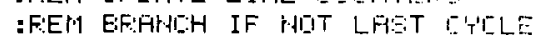
: FEM STEFFIHE MITIF: EIFF

EGE FEM

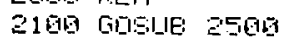

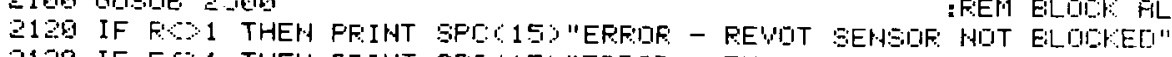

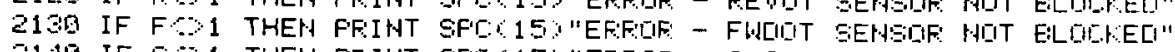

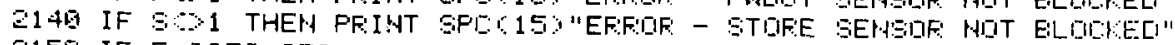

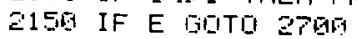

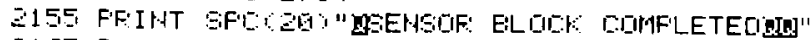

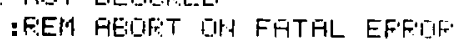

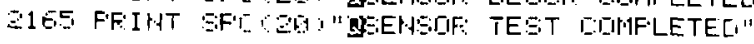




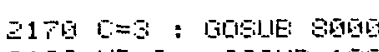

$21 B$ HF:

219 RET RETFH

2132 REM

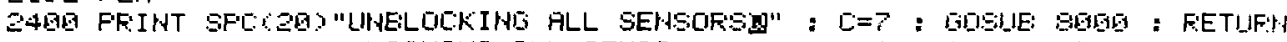

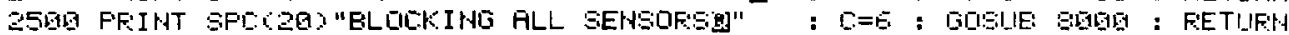

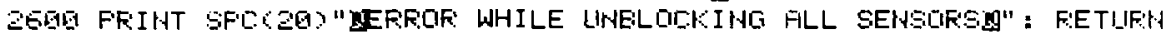

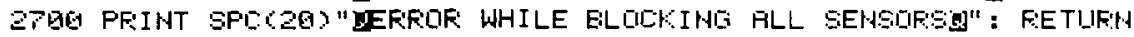

2TSG REM

2796 REM --- MUIVE SOUFEE N INEHES --

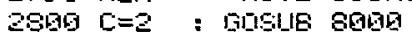

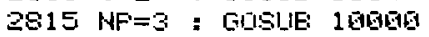

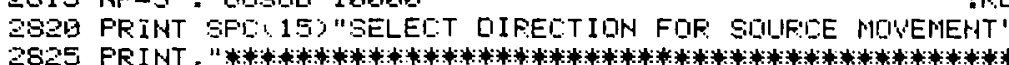

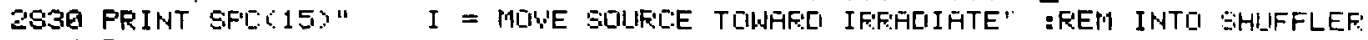

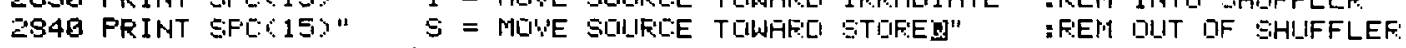

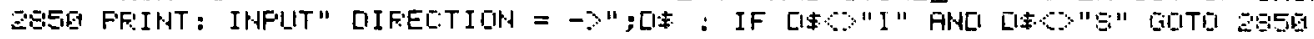

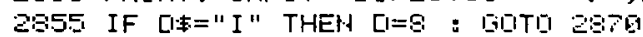

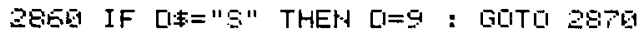

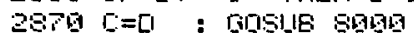

2STS F'F:INT :F.FIIHT

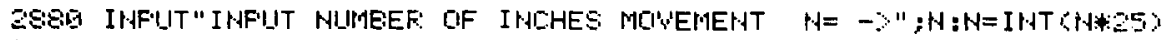

2890 FDR $\mathrm{J}=1$ TO H

$23520=16$ : GOSIIE: Bab

2895 GIOSIIE $960 \mathrm{BO}$

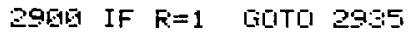

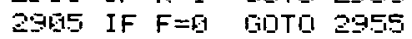

2915 NEFT I

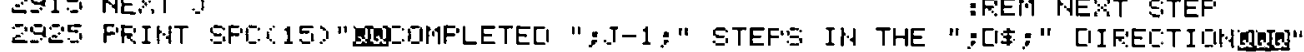

2950 GOTL 29E:

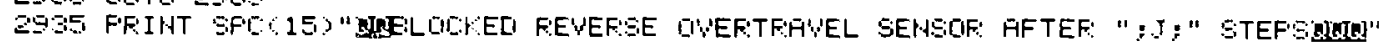
2945 60IT 2965

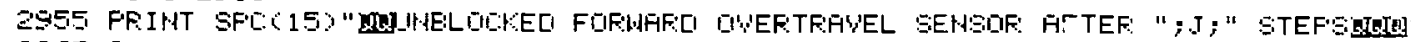

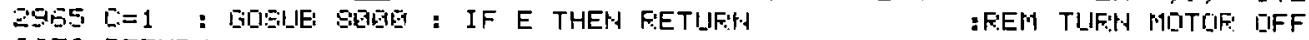

297 B RETLIFH

DGS:B: F:El

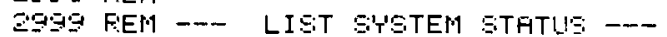

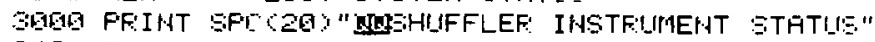

$\because M 1$ I $E S=E$

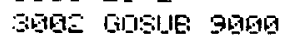

$3063 \mathrm{E}=\mathrm{ES}$

36194 GDSIJE 91 g日,

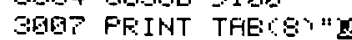

300 IF $S=1$ THEH

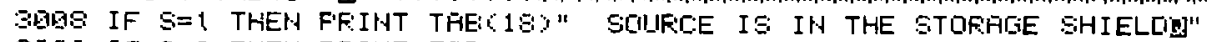

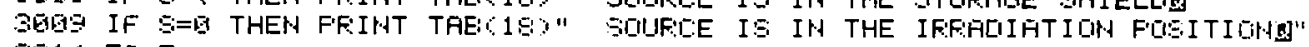

$3614 \mathrm{ES}=\mathrm{E}$

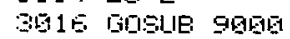

$3615 \mathrm{E}=\mathrm{E} S$

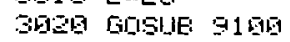

362: IF $F=G$ THEN FFINT THE $15 \mathrm{O}$

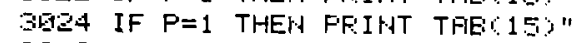

3030 IF $R=0$ THEN FF:IPT TFE $(15) "$

3040 IF $R=1$ THEN FRINT TRE 15:"

305. IF $S=9$ THEN FEIITT THE 15)"

3550 IF $S=1$ THEN FPINT TREC1S;"

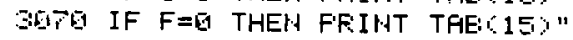

36190 IF $F=1$ THEN PRINT THEC 15?"

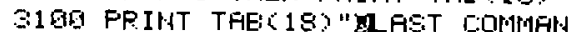

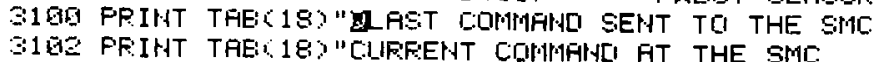

3119 PPIHT TAB

3120 FFINT TFE 18 ) "EF:FOR STATUS E

3136 PRINT TRE(1S)"MOUSE ERRIR STATUS EM

STEFFINIG MOTOR: POWEF: IS OFF"

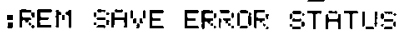

:PEM F:EALI IHPIJTS

IFEVI FEESET EFFIIF: STATLIS:

:FEM FEERI OUITFITE

STEPFING MOTOR FOWEF IS OH"

FEWOT SENSOF: IS UINELCHEKEL"

REWOT SEHSOR IS ELOILELI"

STORE SENSOR: IS UNELOCKEL"

STIORE SENSOR IS BLOCKED"

FWOIT SENSOR IS LINELICKEL"

FHOITT SENSOR IS BLOCKEO"

3150 PFINT : PRIPT SFCO10);

31 EE PRINT"MOIISE OUTFUTS

$31 \mathrm{E} 5$ PFIHT SFCC1日);

3170 FRINT "NOUISE IRIFUTS

CPET TO SME: LCW EYTE=";D:" HICHH E'T'TE=":DE

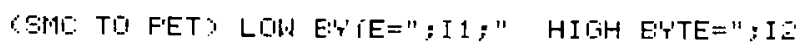




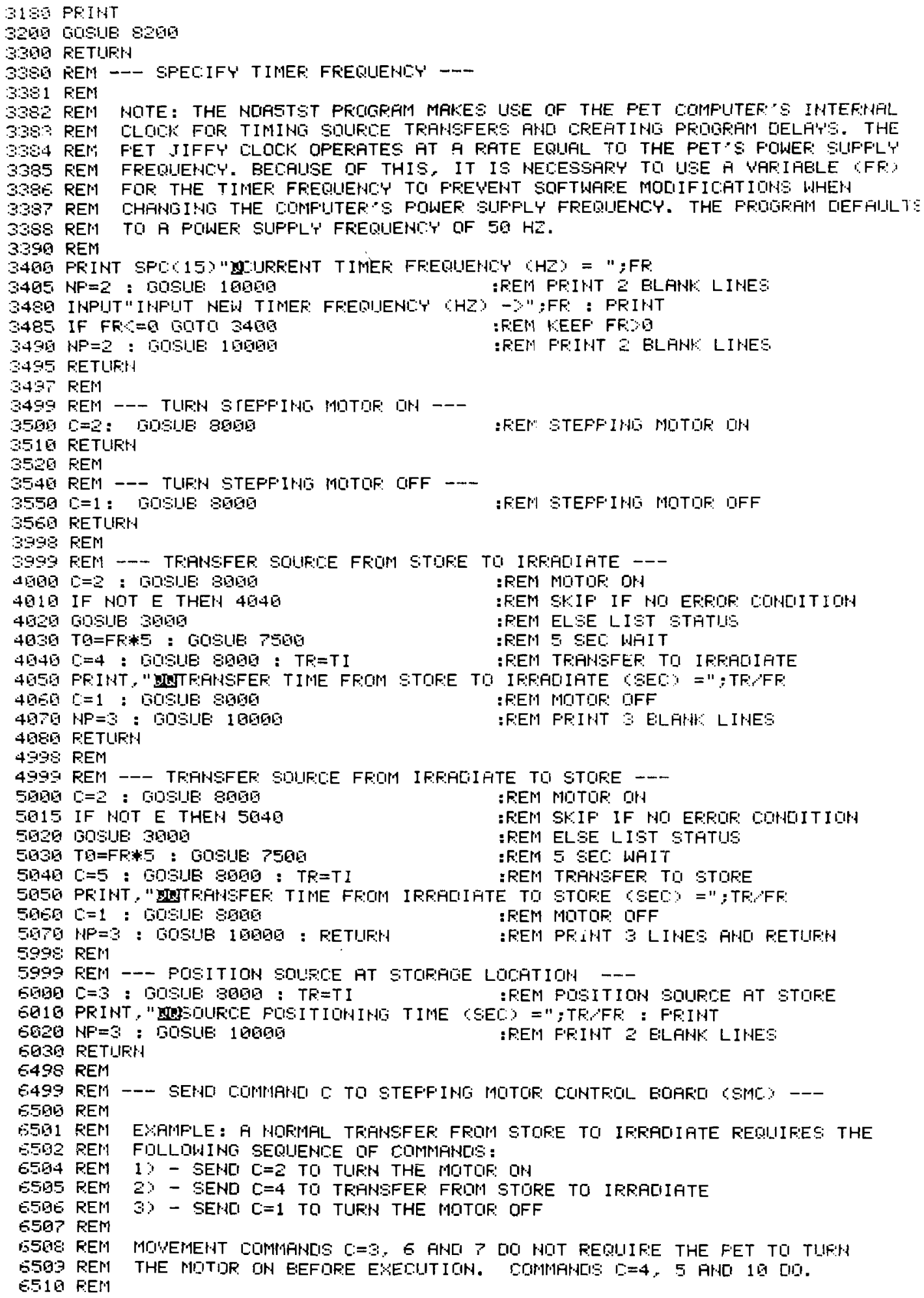




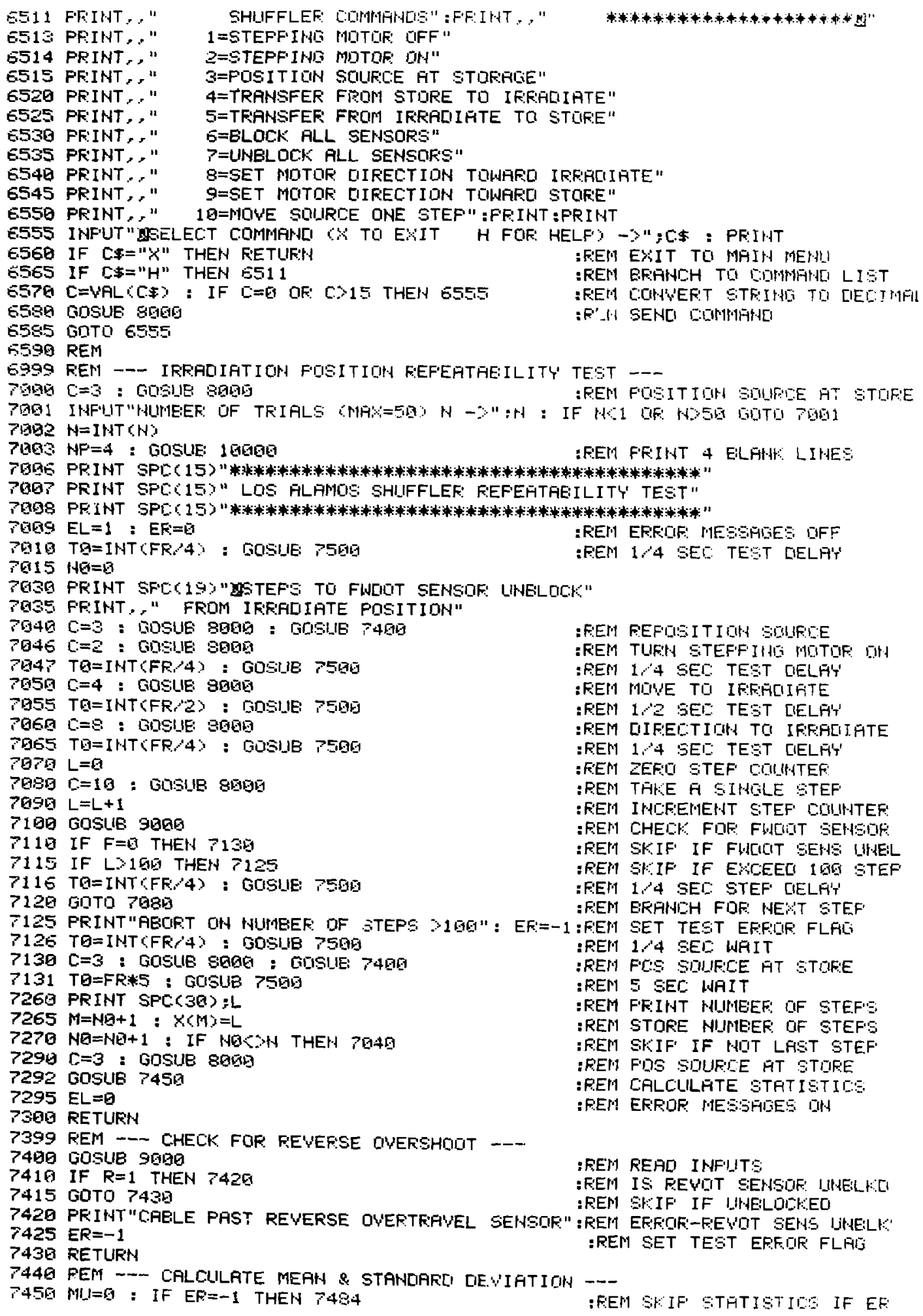
REVERSE OYERTEAYEL SENSOF" :REM EFFGIR-FIEWOT SEHS LWELLK

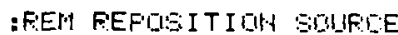
:REM TUFH STEFFIHIS MOTGF: DHA :REM $1 \% 4$ SEC: TEST LELF'T :FEM MLVE TO IFEFICIFTE :REM 12 SEL: TEST [ELF'T :REM CIIFECTIIIY TQ IF:EALIIATE :REM 144 SEL- TEST [IELF'' :FEP ZEFIO STEF COUMTEF: :REM TAHE F SIMTLE STEF :REM I HICFEMENT STEF COHIHTEF: :REM CHELK FDF: FWCIT SEHEIOF :REM SKIF IF FWLITIT SEHS IHHELL PREM SWIF IF ERCEEC 1 GS STEF :FEM 1 \& SEC: STEF [IELF'T' :FEM ERANICH FDF HEQT STEF IREM 1,4 SEI: WFIT :REM FQS SOUIFEE HT STIAEE :REM 5 SEC INAIT :REM FFINT MIIPIEEF OF STEF'E :REM STORE NIJIEER OF STEFS :FEM SKIF IF HOT LAST STEF :REM FIDS SOURIE AT STORE :PEM CALCLILATE STATISTILS

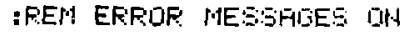

IREM READ INFITS

:FEM IS FEVITT SENSOF: IIMELLLCI REM SET TEST EPFDIR FLFIT

:FEM SHIF STATISTILS IF EF 


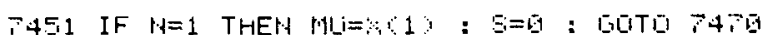

7452 FQR $\mathrm{T}=1$ TO $\mathrm{H}$

7454 MUI=MUI+MOT : NEYT T

745 . $111=1111,1$

$74585=5$

P4E FQF: $\mathrm{T}=1 \mathrm{TO} \mathrm{N}$

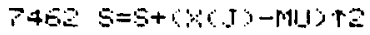

$P 4 B+S=5,(t+1)$

$740=5=S 0 \%$

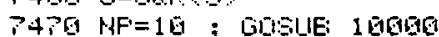

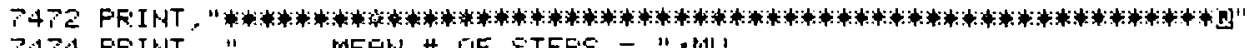

P4P4 PRIHIT. " " MEFH. \# UF פTEFS = ", PIL!

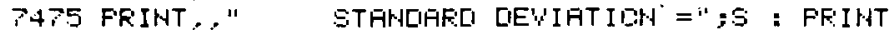

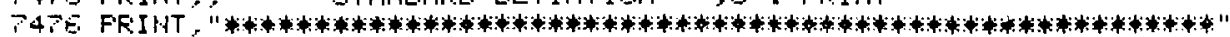

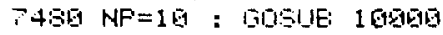

P4S2 GOTO 7490

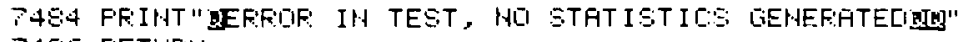

TEE FETLIFIN

PUS FEM

PAGE FEM

P4S' REM

$P 496$ KEM

$7491 \mathrm{~K} E \mathrm{KM}$

$745 \mathrm{RE} M$

7493 REM

7494 FIEl

7495 F:EN

P49E REM

T49G FEM

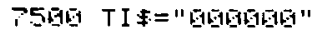

PS1E IF TIST GOTO PS10

TSEG FETURH

7 SOG FEM

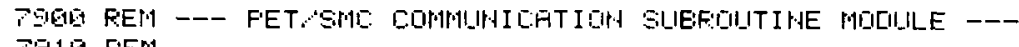

PG19 FEM

$\vec{P}$ CR REM

POSO REM

794 F:EM

7950 FEM

$799 \%$ F:EM

TPS FEM

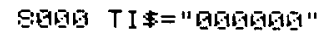

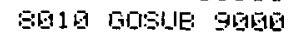

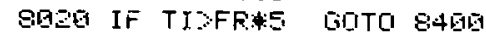

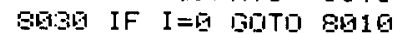

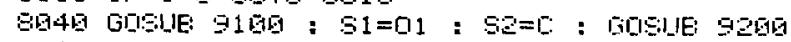

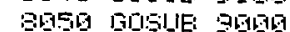

EGES IF TIPFF GOTE 8415

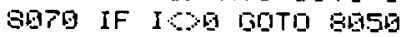

S580 $52=0$ : GOSIJE 9200

8099 GOJOUE gOB⿴囗十

Q169 IF TISFFH15 GOTG 8435

8110 IF I=Q BOTO 8990

8120 IF I $=$ C: THEN RETLIF:H

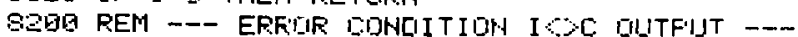

GCES IF I 11 OF: I $\$ 15$ THEN FETURH

Q210 IF EL=1 THEH RETLRH

E215 FF:INT, "Q" ;

3220 마 I-10 GOTO $8341,8242,9243,8244,8245$

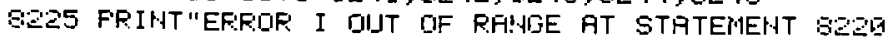

Q230 KEM

8240 REM -- SHUFFLEF ERROF: MESSFIJES ---

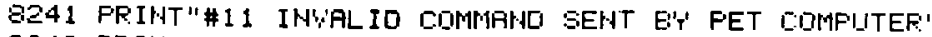

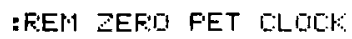

:FEM TOET SME: BTATIIS

:FEM 5 SEL: WHIT LINIT

:FEM WHIT TILL SN1L. FEACI'T'

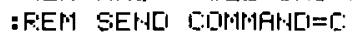

:PEM TIET SIML STTATISS

:FEM 5 SEC WHIT LIMIT

:FEM WFIT FOA: BLCWDOULECIGE=0

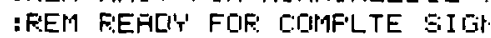

AFEM LET SML STATIJS

:FEM 15 SEC WHIT LIMIT

:REM WAIT FOF COMFLETE SIII

:FEM ECOHFLET I GHA SI INHAL=E:

:REM IF NII EFFEIOF: EETLFIH

:REM IF MESOAILES OIFF FETIIFY

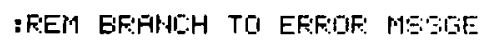

$I=": I$ : PETIIENH

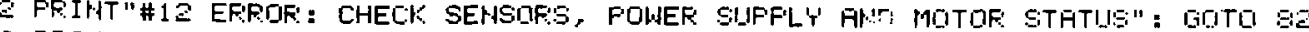

G'43 FPINT"\#13 AN OVERTFRWEL SEHSOR FHILEO TO STOP STEF":" : DOTO

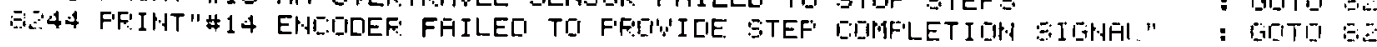




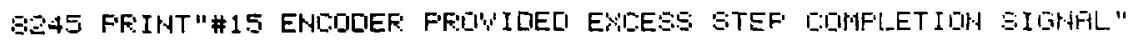

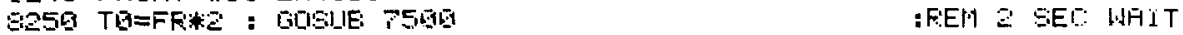

BSEG F:ETURN

839T REI

8399 FEM -- PRINT COMMUNICFTION ERFIOR: MESSFIGE ---

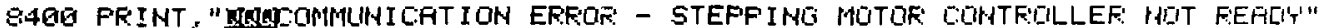

84. G GOITO 8465

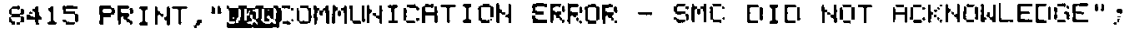

8425 PRINT" PET CIMMANI"

8430 GOTO 8465 :FEM FITTE:TF' A REESTHFT

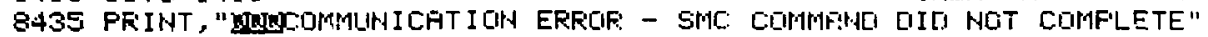

8445 GOTO 8455 :FEN ATTEHFT H FESTFET

8460 REM - - SYSTEM IS LOST - FTTEMFT AN IHTERRIFT F:ESTFIRT - -

8465 GOSUE GGQG

3479 TO=FR*3 : GOSUB 7500 :FEM S SEC WAIT

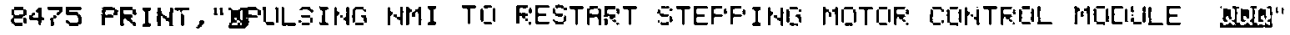

848O TO=FRH : GOSLIE $75 S G$ :FEM Z SEC WFIT

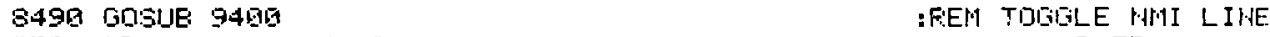

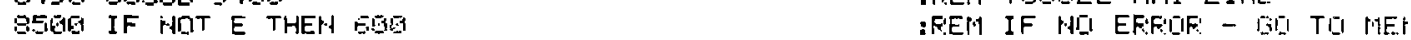

8SQ5 $E=-1$ :PEM SET EFFILF: FLRL

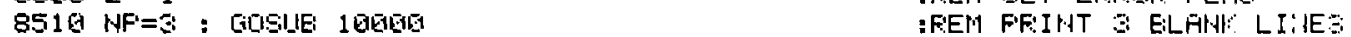

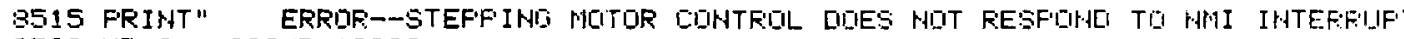

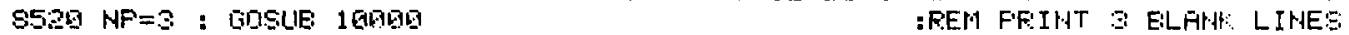

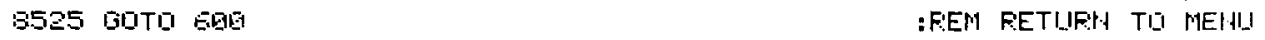

8999 REP

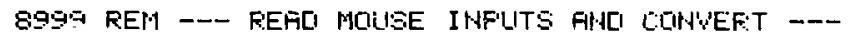

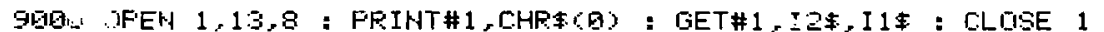

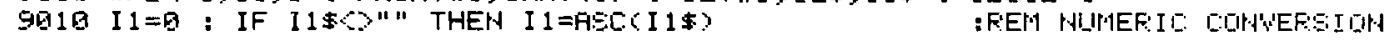

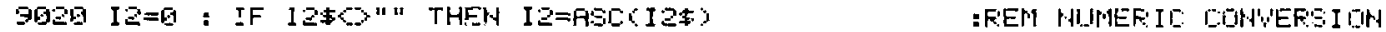

$969 \mathrm{R}=(\mathrm{I} 2 \mathrm{ANCI} 1)$

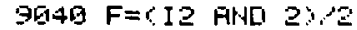

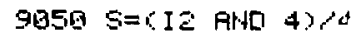

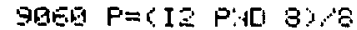

G日7\% I= I2 AND 240$) 1 \mathrm{E}$

SBSB $E=B$ : IF IO=11 THEH $E=-1$

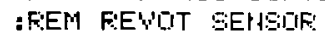

:FEM FWEIIT SEHSIISE

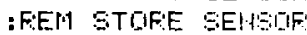

:FECI F'DUEF: D.PW'UFF

:FEM SHI_IFFLEF: TO F'ET IFAFI

9590 RETUF:H

:FEM SET EFFIOF FLFE

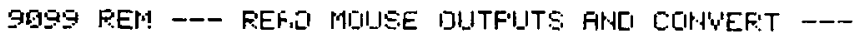

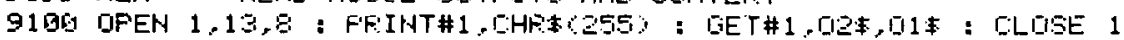

$911901=0$ : IF $0150 "$ THEN O1=ASI:CO1\$?

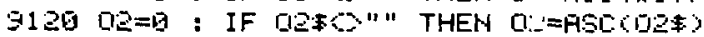

9130 0=02 FHAI 15

:FEM HUMEFIE COHWEF:SI INH

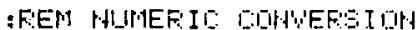

9149 RETLIRN

$9198 \mathrm{REM}$

9199 F:EM -- SET MDUSE DUTFUITS ---

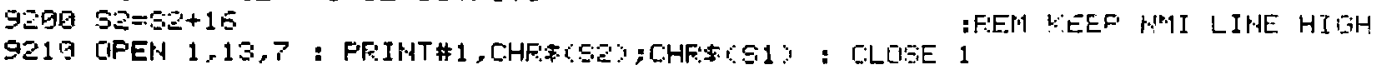

9229 RETIIFI.

939: REM

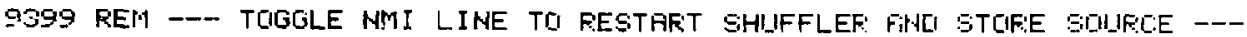

3409 GDSUE 9109 :PEM FEALI MOHSE TOI DET DI

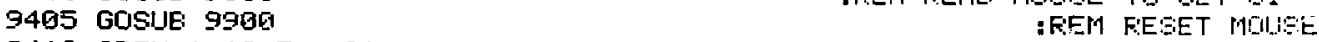

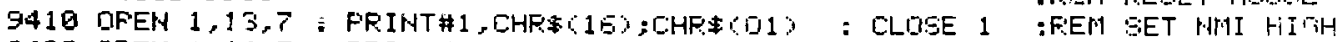

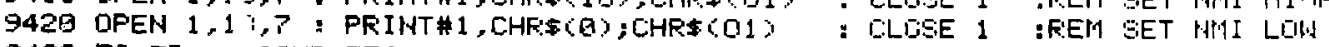

9430 TQ=FR : LDSUE 75GQ

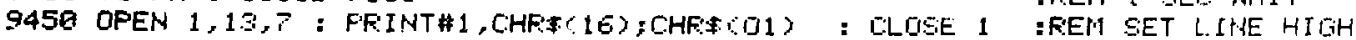

9460 GOSHIE 9 MOD

346.5 IF I $9 \mathrm{~S}$ THEH 9485

9458 CODSUE: 3099

9470 TE=FPHA : GCSLIE 7509

3450 RETURTI

9485 TG=FR*5 : GOSUE 75019

9487 GDSLILE IEGO

9488 IF I $C 9 \pi$ THEN $E=-1$

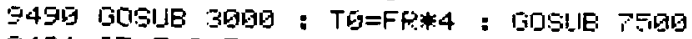

9491 IF $E=G$ THEN RETURH

9492 FEM -- NHI ERPBD LISTIHIS -:FEM TIET ENIL STATUIE :REM GRIF IF FLFIL :FEM I IST STHTILE :REW 4 SEC WHIT

IREM 5 SEE: TIMEIIITT :PEM FEREFI STATIIS IFEM EREIOE: IF I $\%$ :FEEY LIST STATILS -FEM SYIF IF HIO EFEOI 


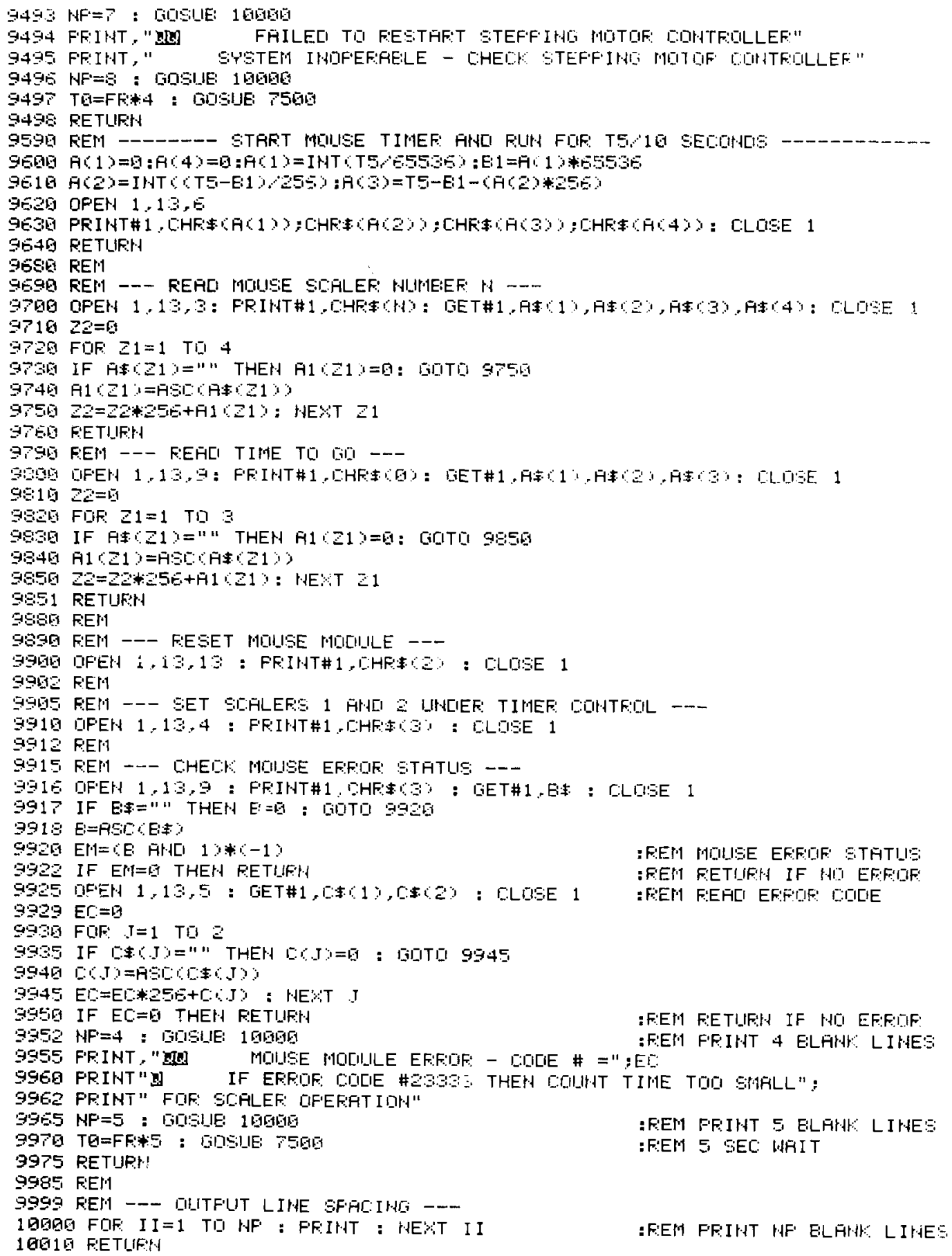

19GQG FOF II=1 TI NF : FEIHT : HEYT II AFEM FFIHT WF ELFHA LIHES

:FEYI FRIHT 5 ELAHH: LIHAS :FEM 5 SEC WHIT 